\title{
BIOMECHANICS OF FOETAL MOVEMENT
}

\author{
N.C. Nowlan* \\ Department of Bioengineering, Imperial College London, London, UK
}

\begin{abstract}
Foetal movements commence at seven weeks of gestation, with the foetal movement repertoire including twitches, whole body movements, stretches, isolated limb movements, breathing movements, head and neck movements, jaw movements (including yawning, sucking and swallowing) and hiccups by ten weeks of gestational age. There are two key biomechanical aspects to gross foetal movements; the first being that the foetus moves in a dynamically changing constrained physical environment in which the freedom to move becomes increasingly restricted with increasing foetal size and decreasing amniotic fluid. Therefore, the mechanical environment experienced by the foetus affects its ability to move freely. Secondly, the mechanical forces induced by foetal movements are crucial for normal skeletal development, as evidenced by a number of conditions and syndromes for which reduced or abnormal foetal movements are implicated, such as developmental dysplasia of the hip, arthrogryposis and foetal akinesia deformation sequence. This review examines both the biomechanical effects of the physical environment on foetal movements through discussion of intrauterine factors, such as space, foetal positioning and volume of amniotic fluid, and the biomechanical role of gross foetal movements in human skeletal development through investigation of the effects of abnormal movement on the bones and joints. This review also highlights computational simulations of foetal movements that attempt to determine the mechanical forces acting on the foetus as it moves. Finally, avenues for future research into foetal movement biomechanics are highlighted, which have potential impact for a diverse range of fields including foetal medicine, musculoskeletal disorders and tissue engineering.
\end{abstract}

Keywords: Foetal movement, fetal movement, bone development, joint development, developmental dysplasia of the hip, arthrogryposis, biomechanical models, computational simulation, mechanical properties of foetal tissues, mechanical properties of fetal tissues.

\footnotetext{
*Address for correspondence:

Dr N. C. Nowlan

Department of Bioengineering

Imperial College London

London SW7 2AZ

United Kingdom
}

Telephone Number: +44 (0) 2075945189

FAX Number: +44 (0) 2074949817

E-mail: n.nowlan@imperial.ac.uk

\section{Introduction}

Foetal movement has long been of interest to the medical and scientific communities as a possible measure of foetal health and of neurobehavioral development. However, the influence of the physical environment of the foetus on its movements, and the biomechanical role that those movements play in foetal development, is seldom addressed directly. This is despite the important role that foetal movement is thought to play in commonly occurring postnatal musculoskeletal conditions, such as developmental dysplasia of the hip (DDH) and arthrogryposis. In this review, a biomechanical perspective on foetal movement is presented, including how foetal movements are affected by aspects of the physical environment, and an overview of the downstream effects of reduced foetal movement on skeletal development. The primary aims of this review are 1) to investigate the effects of intrinsic and external stimuli and conditions on foetal movements, 2) to discuss the most common conditions in which abnormal gross foetal movements and musculoskeletal conditions are comorbid, with particular focus on the causality between movement changes and musculoskeletal abnormalities, and 3) to survey any biomechanical analyses pertaining to foetal movements or the physical environment of the foetus. Papers selected for discussion include those that relate to human foetal movement patterns; specifically the normal range, the change over time and the measurement of limb and spine foetal movements, in addition to the effects of intrinsic, internal and external factors on foetal movements. A survey of the literature on peri- and post-natal conditions in which abnormal foetal movements and abnormal musculoskeletal development are comorbid was performed, initially using search tools (Pubmed, Google Scholar), followed by an iterative exploration of the literature cited within the papers found. The most common conditions were identified as DDH, arthrogryposis and foetal akinesia deformation sequence (FADS). These conditions, with particular focus on aetiology, risk factors, diagnosis and treatment, and animal models, are surveyed in this review. A further condition, bone disease of prematurity, for which there is some indication of a link between movements and musculoskeletal development, is also discussed briefly. Finally, the literature relating to the biomechanical analyses of foetal movements and the foetal tissues and environment was selected for inclusion in the review.

\section{Foetal Movement}

The first foetal movement is a sideways bending of the foetus which has been observed at about 7 weeks, 
while most movements have started by 10 gestational weeks (reviewed in de Vries and Fong, 2006). Foetal movements include general body movements, startle and twitch movements, isolated limb movements, breathing movements, hiccups, isolated head and neck movements, sucking and swallowing, jaw movements (including yawning), hand-face contact, stretch and rotation (de Vries et al., 1982). All of these patterns occur by 15 gestational weeks, and maternal sensation of movement usually commences after 16-18 weeks (de Vries et al., 1982). It has been commonly reported that foetal movements decrease in frequency after a peak in the second trimester (Hayat et al., 2011; Natale et al., 1985; Ten Hof et al., 2002; Zoia et al., 2007), but other studies have not found large or significant decreases in movements over gestation (Arduini et al., 1986; Patrick et al., 1982). There is considerable variance in the literature for quantification of the proportion of time that the foetus is active and the average number of movements per time segment, which has been suggested to be due to differences in study design, data analysis and varying definitions of what constitutes a single movement (Ten Hof et al., 1999). The number of movements in a healthy foetus has been suggested to vary from 4 to 100 movements per hour (Mangesi and Hofmeyr, 2007), but the normal range of normal movement incidence is unclear (Hijazi and East, 2009). A study from De Vries et al. (1988) characterised both inter- and intra- foetal differences in 12 healthy pregnancies between 7 and 37 weeks using ultrasound. The study showed that the onset and differentiation of specific movement patterns, such as a startle movement, jaw opening or isolated arm or leg movements, were very similar between foetuses and were age-dependant. However, quite substantial differences in the total activity and incidence of general movements were found, with some foetuses being much more or less active than the group average. The proportion of time in which the foetus was engaged in each of the specific movement patterns tended to fluctuate between monitoring sessions, indicating substantial intra-individual differences (de Vries et al., 1988). Therefore, both intra- and inter-individual differences in foetal movement activity exist.

The gold standard means of objectively quantifying and characterising foetal movements in real-time is with real-time ultrasound (de Vries et al., 1982). In recent years, foetal cine MR imaging has also been used to assess foetal movements patterns. This imaging technique offers an exceptional tool for visualising foetal movements due to the ability to simultaneously view movements of the foetal limbs, head and trunk, even in late gestation (Guo et al., 2006; Hayat et al., 2011), but cannot yet be used in real time analyses of foetal movements. Accelerations and decelerations of the heart rate, as measured by cardiotocograph (CTG), are routinely used antenatally to predict foetal movements (Flynn et al., 1982; Olesen and Svare, 2004). However CTG is inferior to ultrasound and MRI as a means of reliably monitoring foetal movements, as the correlation between heart rate changes and foetal movements is fallible; for example, heart rate changes due to foetal vibroacoustic stimulation have been observed despite the lack of movement in a pathological case of foetal akinesia (Sherer et al., 1992). Maternally sensed decreased foetal movements are a common reason for consultation with obstetric services (O'Sullivan et al., 2009), but maternal perception of movement is variable, with studies reporting widely ranging values for the proportion of movements simultaneously detected by ultrasound and sensed by the mother (Hertogs et al., 1979; Rayburn and McKean, 1980). Nevertheless, foetal movements are an important measure of foetal health. Two recent studies reported that $22-25 \%$ of women perceiving decreased foetal movements had poor outcomes at birth, such as preterm births or low birth weight babies (Dutton et al., 2012; O'Sullivan et al., 2009). It has been suggested that decreased foetal movements may be "a warning sign of impending foetal death" (Whitworth et al., 2011), and $57 \%$ of stillbirths in one particular study (Efkarpidis et al., 2004) were preceded by decreased foetal movements. Due to their importance for musculoskeletal development, this review will focus mainly on the movements of the limbs or spine, whether isolated or forming part of a general movement, rather than movements such as swallowing or breathing movements.

\section{Physical Influences Affecting Foetal Movement}

Besides the inherent neuromuscular function of the foetus, there are three major physical influences that have been shown to affect foetal movement; the amount of free intrauterine space, the amount and location of the amniotic fluid and foetal positioning. A range of external influences have been shown to affect foetal movement patterns, and there is some evidence to suggest gender differences in foetal movement patterns. Each of these factors will be discussed herein.

\section{Intra-uterine space and amniotic fluid}

Free space not occupied by the foetus in the womb is filled with amniotic fluid, and therefore the amount of space that the foetus has available for movement depends on the volumes of the womb, foetus and amniotic fluid. It has been suggested that the amniotic fluid distends the uterus, enabling the foetus to move without constriction as it grows (Moh et al., 2012). A recent study from Hayat et al. (2011), having optimised a cine MR imaging protocol for visualising foetal movements, investigated the correlation between intra-uterine space and foetal movements in cine-MRI sequences of 37 healthy foetuses between 20 and 37 weeks of gestation. The authors found a significant decreasing trend in movement frequency with gestational age, a finding which has also been shown in ultrasound studies of foetuses with a similar age range (Ten Hof et al., 2002). From mathematical analyses of the MR images, the authors calculated that the ratio of the foetal to free-uterine space volumes doubles between 18 to 37 gestational weeks, and proposed that the reduction in the uterine space could explain in part the reduction in movement (Hayat et al., 2011). Foetuses younger than 32 gestational weeks displayed both small and large amplitude movements with unimpeded joint and spine extensions, making use of all free space. As foetuses approached term, they appeared cramped (Fig. 1), movements became 

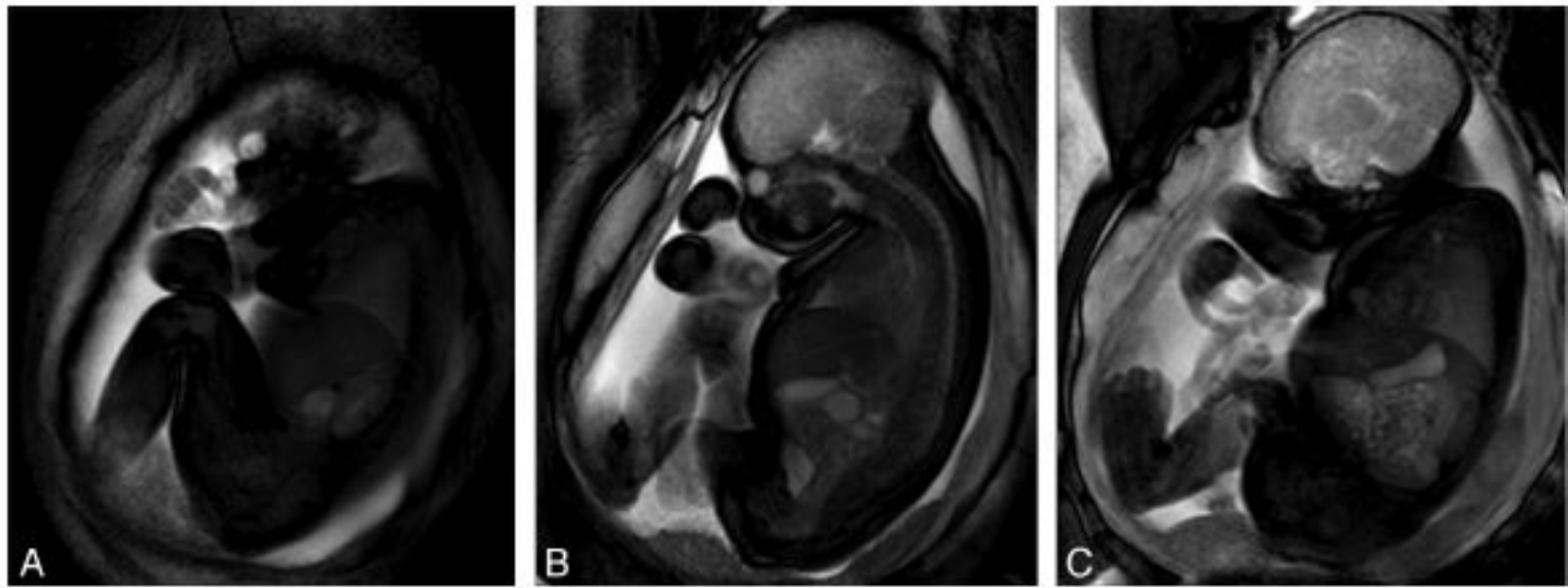

Fig. 1. Successive frames from a multi-section cine MR image sequence of a 36 week gestational age foetus. Adapted from an image reproduced with permission from Hayat et al. (2011).

smaller, and major joint movements were restricted to rotations and attempts to extend the spine (Hayat et al., 2011). The authors conclude that the physical and spatial constraints of the uterus are likely to significantly affect foetal movements, and discuss how the constraints would vary between premature and full-term foetuses. Studies have shown that preterm infants have both a greater range of motion during kick movements (Heriza, 1988) and a greater kick frequency than full term infants at comparable ages after birth (Geerdink et al., 1996), and Hayat et al. (2011) propose that these differences are related to the difference in in utero constraints experienced prior to birth between preterm and full term infants, where the full term infants experience higher levels of constraint.

Amniotic fluid volume increases progressively between 10 and 28 weeks of gestation, is maintained between 29 and 37 weeks and decreases sharply after 39 weeks (Beall et al., 2007a). Oligohydramnios is a serious deficiency of amniotic fluid (Moh et al., 2012), which can result from amniotic rupture or amniotic fluid leak, or decreased amniotic fluid production due to placental hypoperfusion or foetal anuria (Moh et al., 2012). Sival et al. (1990) did a longitudinal study of 19 pregnancies affected by premature rupture of the amniotic membranes, where foetal movements were monitored with weekly ultrasound scans, and found that the severity of amniotic fluid reduction was correlated with changes in general foetal movements. Moderate reduction of amniotic fluid was associated with a decrease in the amplitude of general movements, while a more severe reduction in fluid was associated with a reduction in both the speed and the amplitude of movements (Sival et al., 1990). Foetal breech position was associated with the more severe categories of oligohydramnios, and tended to have severe reductions in the amplitude of movements (Sival et al., 1990). Multiple joint contractures are commonly associated with oligohydramnios (Palacios and Rodriguez, 1990). Hayat et al. (2011) found that during late gestation, amniotic fluid relocates mostly to the foetal thorax, which the authors suggested may facilitate upper limb movements and trunk extensions. The relationship between foetal movements and amniotic fluid can be complex: reduced movements due to placental hypoperfusion (decreased supply of oxygen by the placenta) can itself lead to a reduction in amniotic fluid and oligohydramnios (Baschat, 2004), in which case the original cause for reduced movements would be placental insufficiency rather than oligohydramnios.

\section{Foetal position}

Breech foetal position is a common occurrence of movement restriction in the human foetus, and has been shown to have a transient influence on the range of movement of the lower limbs, and on the stability of the hip joint. There are three common types of breech, illustrated in Fig. 2; extended (also known as frank) breech where the hips are in flexion and the knees in extension, flexed (or complete) breech where both hips and knees are flexed, and footling breech, where one or both feet come first. Luterkort et al. (1986) performed repeated ultrasound scans on 222 foetuses in the breech position at 33, 35 and 38 weeks, and correlated leg positioning and delivery mode with hip instability. The authors found that foetal breech position, rather than breech delivery, is a risk factor for hip instability. Extended breech was found to be worst for hip dysplasia (Luterkort et al., 1986). Foetal breech position has also been shown to have effects on limb movements and positioning after birth. Sekulic et al. (2009) compared the range of motion and some reflexes between breech and occipital births between 2 and 4 days after birth, and found a decreased range of movements in the breech group, particularly in the lower limb. Fong et al. (2009) found that at 2, 4 and 6 weeks after birth, breech babies spend significantly more time in a flexed hip posture and significantly less time in an extended hip posture than cephalic presentation babies, while no difference in knee extension was found between the groups. From 12 weeks on, no significant differences were found between the groups (Fong et al., 2009). Sival et al. (1993) also found significant effects on hip extension in foetal breech position infants up until 12 weeks after birth. The long term effects 


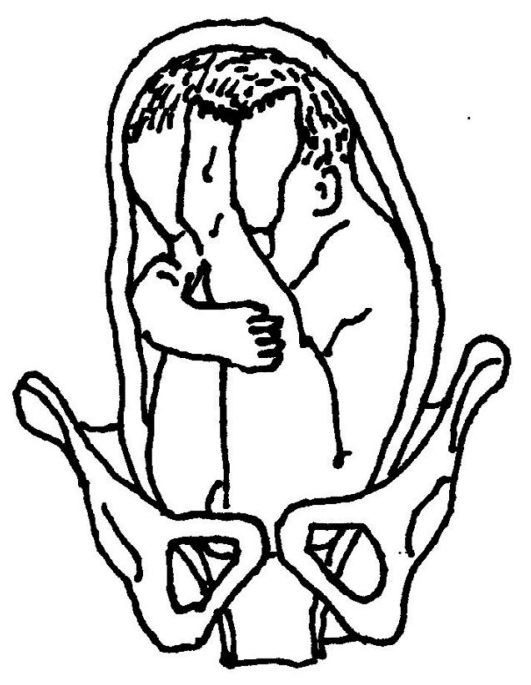

Extended Breech

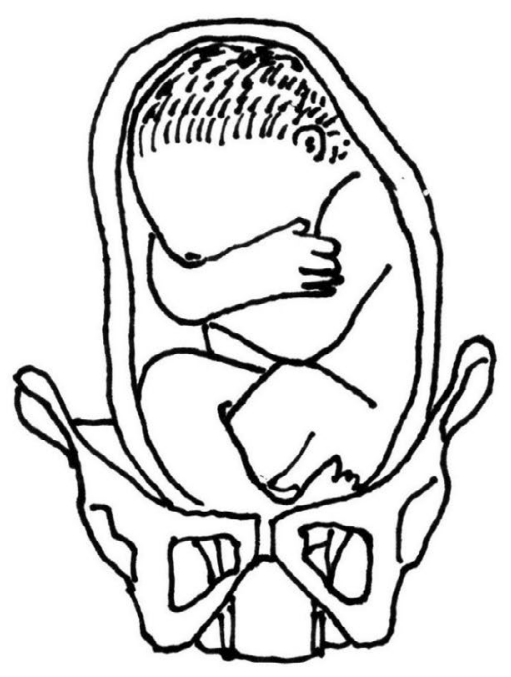

Flexed Breech

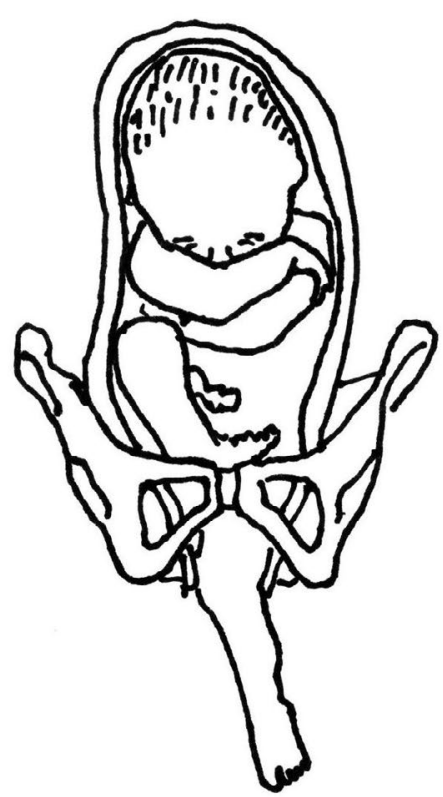

Footling Breech

Fig. 2. Foetal breech positions.

of breech foetal position were assessed by Fong et al. (2008), who characterised locomotion in children with an average age of 2.5 years. The study showed that there were no differences between walking patterns between breech and control groups, but that during a functional task (gap crossing), the children who had been in a breech foetal position exhibited less extra hip flexion than in the control group, with all other gait analysis parameters remaining equal between the groups. The authors suggest that this may indicate that the breech group flex their hip less and extend more, or else that they walk with a more flexed position. However, the authors highlight the relatively small number of subjects ( $n=10$ for breech group and $n=11$ for control group) (Fong et al., 2008), and it is likely that greater numbers are needed to verify if a foetal breech position does have long term effects on locomotion. Interestingly, while the lower limbs are more restricted in a foetal breech position, the upper limbs are likely to have more space as compared to a cephalic presentation, and it has been shown the wrists of breech foetuses are less flexed than those of cephalic after 36 gestational weeks (GW) (Fong et al., 2005a). The position and shape of the foetal head in late gestation have also been shown to be affected differently in breech and cephalic positions, where those in a breech foetal position are less likely to adopt a lateralised head position as compared to those in a cephalic position (Fong et al., 2005b). Breech foetuses were also shown to have slightly more elongated heads than cephalic foetuses, which likely reflects differences in the local mechanical environment of the skull, due to the fact that while the cephalic skull engages with the maternal bony pelvis, the skull of a breech position foetus is surrounded by soft tissue at the upper side of the uterus (Fong et al., 2005b).

\section{Gender}

Foetal movements may be more frequent or more pronounced in male foetuses than in female foetuses. Almli et al. (2001) performed longitudinal quantification of leg movements for 37 subjects at 30, 34 and 37 weeks gestational age using ultrasound. At weeks 30 and 37, the mean number of leg movements per minute was found to be significantly lower in females as compared to males, while at week 34 the average was lower for females than for males but was not statistically significant. Buss et al. (2009) also examined gender-specific movements; in this case, the startle response as measured by foetal heart rate in response to vibroacoustic stimulation applied to the mothers abdomen. The authors found differences between the genders in response to vibroacoustic stimulation, with males showing significantly larger responses than females at 31 and 37 weeks of gestation. However, the small numbers of subjects and the limited duration of the monitoring periods in these studies mean that a definitive conclusion on gender differences in foetal movements cannot be reached as yet.

\section{External influences affecting foetal movements}

The two main external influences shown to be capable of affecting some foetal movements are maternal consumption and acoustic stimulation. Foetal breathing movements, but not gross foetal body movements, have been shown to be affected by increased maternal glucose levels (Bocking et al., 1982; Lewis et al., 1978), indicating that blood sugar levels may not affect gross movements. Similarly, foetal body movements are unaffected by maternal alcohol consumption, while foetal breathing and eye movements are transiently affected (McLeod et 
al., 1983; Mulder et al., 1998). Short-term administration of caffeine has no effect on foetal body or breathing movements, while long term caffeine consumption may lead to increased foetal breathing activity (McGowan et al., 1987). An association between cigarette smoking and decreased foetal breathing movements has been reported (Manning et al., 1975; Ritchie, 1980), but the effects of smoking on gross foetal movements have not been assessed. Maternal methadone administration has been shown to reduce foetal motor activity (Jansson et al., 2005), and selective serotonin reuptake inhibitor (SSRI) use, a treatment for maternal depression, has been shown to lead to more jerky gross movements and fewer foetal breathing movements (Salisbury et al., 2009). Maternal cocaine or methamphetamine usage decreases placental blood flow and therefore reduces the supply of oxygen to the foetus (Salisbury et al., 2009), which would likely lead to reduced foetal movements.

Methods such as manual manipulation and vibroacoustic stimulation have been used to bring the foetus to a more active cycle for clinical screening purposes. Manual manipulation, which involves physical shaking or movement of the uterus, was reported by Piyamongkol et al. (2006) to increase foetal reactivity, but a Cochrane review (a systematic review and meta-analysis of intervention studies, and not including observational studies) by Tan and Sabapathy (2001) of three trials with a total of 1100 women with 2130 episodes of participation found no significant benefit in increasing foetal reactivity. In another Cochrane review (Tan and Smyth, 2001), foetal vibroacoustic stimulation, where a handheld electronic device is used to transmit brief sound stimuli to the foetus, was, however, found to evoke significantly more foetal movement.

\section{Biomechanics of Prenatal Skeletogenesis}

The prenatal development of the human skeleton was described in outstanding detail by Bardeen (1905) and with Lewis (Bardeen and Lewis, 1901) in two ground-breaking papers from the very start of the $20^{\text {th }}$ century. These papers reveal key events of skeletogenesis during the embryonic period, which comprises the first ten gestational weeks. All skeletal elements (apart from some distal phalanges) are present in cartilaginous form by 8.5 gestational weeks (Bardeen and Lewis, 1901) (conversion from crown to rump length to gestational age from Hadlock et al., 1985), and at this stage joint shapes already roughly resemble their adult forms (Bardeen, 1905; Bardeen and Lewis, 1901). Independent limb movements commence at around 9 gestational weeks (de Vries and Fong, 2006), which coincides with the same point at which long bone primary ossification centres initiate (Bagnall et al., 1982; Bardeen and Lewis, 1901). Cavitation of major joints occurs at 10 gestational weeks (Bardeen and Lewis, 1901; O'Rahilly and Gardner, 1975), and further refinement of joint shapes occurs throughout gestation (Ráliš and McKibbin, 1973). Any prolonged or systemic reduction in foetal movements can affect skeletal development. At the most severe end, the fatal condition foetal akinesia deformation sequence (FADS) occurs with highly abnormal or absent foetal movement. A substantial reduction in foetal movement can lead to arthrogryposis, a syndrome where multiple joint contractures are present. The hip joint is particularly dependant on foetal movements, with the most common congenital musculoskeletal abnormality being developmental dysplasia of the hip (DDH). The risk of DDH is thought to be strongly linked to abnormal movement or intrauterine conditions. These conditions are interlinked, as in the most severe cases of FADS, arthrogryposis and DDH are likely to be present, while abnormal development of the hip (i.e., DDH) frequently occurs in cases of arthrogryposis. These conditions are summarised in Table 1 and are discussed in detail below. The effect of premature birth on bone mineralisation is also discussed in the context of in utero biomechanical stimulation.

\section{Foetal Akinesia Deformation Sequence (FADS)}

\section{Aetiology}

FADS, also known as Pena-Shokeir syndrome, is a rare, non-specific syndrome with severely abnormal, or absent, foetal movements as its common denominator. The incidence of FADS has been found to be 1:15 000 in a retrospective population-based study (Bayat et al., 2009). The main symptoms of FADS include multiple joint contractures, craniofacial deformities, abnormal volume of amniotic fluid, pulmonary hypoplasia, and intrauterine growth restriction (Hall, 2009). Focussing specifically on the skeleton, common symptoms include thin bones which are prone to fracture, clenched hands with adducted thumbs and scrambled fingers, congenital talipes equinovarus (club foot), and flexed or extended joint contractures (reviewed in Hall, 2009). Congenital kyphosis scoliosis and other spinal abnormalities have been reported (reviewed in Hall, 2009). Radiographic and histological analyses by Rodriguez et al. (1998a) of eleven newborns who died due to complications arising from conditions of foetal immobility (due to spinal muscular atrophy, primary myopathic process and congenital myotonic dystrophy) revealed that the long bones were slender and hypomineralised. Multiple long bone fractures were detected in the infants with spinal muscular atrophy or a primary myopathic process, while no diaphyseal fractures were detected in those with congenital myotonic dystrophy (Rodriguez et al., 1998a). Most fractures were presumed to be due to delivery and postnatal handling, but there was evidence to suggest that some growth plate fractures may have occurred in utero (Rodriguez et al., 1998a). A detailed morphometric study of the bones revealed that the long bones from the immobile group were of the same length as age matched controls, but had a decreased cortical thickness and cortical area (Rodriguez et al., 1988b).

There have been several studies in which the foetal movement patterns in foetuses suffering from FADS have been described. 2D ultrasound is the most common imaging modality, but MRI (Nemec et al., 2011) and 4D ultrasound (Ruano et al., 2003) have also been used. The time of onset of abnormal movements varies between foetuses, with 
Table 1. Summary of featured musculoskeletal conditions in which reduced or abnormal foetal movement (FM) is comorbid.

\begin{tabular}{|c|c|c|c|c|}
\hline & Incidence & \begin{tabular}{|l|}
$\begin{array}{l}\text { Effects on } \\
\text { musculoskeletal system }\end{array}$ \\
\end{tabular} & $\begin{array}{l}\text { Effects on fetal movements } \\
\& \text { measurement techniques }\end{array}$ & Possible causal pathways \\
\hline FADS & $\begin{array}{l}1 \text { per } 15000 \\
\text { (Bayat et al., } \\
\text { 2009). }\end{array}$ & $\begin{array}{l}\text { Slender, } \\
\text { hypomineralised } \\
\text { bones; mutiple joint } \\
\text { contractures; congenital } \\
\text { talipes equinovarus }\end{array}$ & $\begin{array}{l}\text { Severe reduction in, } \\
\text { abnormal, or complete } \\
\text { absence of FM. Measured } \\
\text { using ultrasound (see text for } \\
\text { references) }\end{array}$ & $\begin{array}{l}\text { a) } \begin{array}{l}\text { Neurogenic/myogenic/connective tissue } \\
\text { pathology }=>\text { abnormal movements }=>\end{array} \\
\text { musculoskeletal abnormalities } \\
\text { b) Unknown causes }=>\text { abnormal movements } \\
\Rightarrow>\text { musculoskeletal abnormalities } \\
\text { c) Unknown causes }=>\text { contractures }=> \\
\text { abnormal movements }=>\text { musculoskeletal } \\
\text { abnormalities }\end{array}$ \\
\hline Arthrogryopsis & $\begin{array}{l}1 \text { per 3000-5000 } \\
\text { (Lowry et al., } \\
2010)\end{array}$ & $\begin{array}{l}\text { Joint contractures in two } \\
\text { or more body parts }\end{array}$ & $\begin{array}{l}\text { Reduced/restricted/ } \\
\text { abnormal FM due to neural, } \\
\text { muscular or connective } \\
\text { tissue disorders, vascular } \\
\text { compromise, intrauterine } \\
\text { environment or unknown } \\
\text { causes. Movements measured } \\
\text { using ultrasound in small } \\
\text { number of affected fetuses } \\
\text { (see text for references) }\end{array}$ & $\begin{array}{l}\text { a) } \begin{array}{l}\text { Neurogenic/myogenic/connective tissue } \\
\text { pathology }=>\text { abnormal movements }=>\end{array} \\
\text { contractures } \\
\text { b) Environmental factors }=>\text { restricted } \\
\text { movements => contractures } \\
\text { c) Vascular/hypoxic event }=>\text { abnormal } \\
\text { movements => contractures } \\
\text { d) Maternal illness or drug use => abnormal } \\
\text { movements => contractures } \\
\text { e) Unknown causes => abnormal movements } \\
=>\text { contractures } \\
\text { f) Contractures }=>\text { abnormal movements } \\
=>\text { aggravated contractures }\end{array}$ \\
\hline DDH & \begin{tabular}{|l|}
1.3 per 1000 \\
$($ Dezateux and \\
Rosendahl, 2007)
\end{tabular} & $\begin{array}{l}\text { Unstable, partially or } \\
\text { fully dislocated, or } \\
\text { malformed hip joint }\end{array}$ & $\begin{array}{l}\text { Many identified risk factors } \\
\text { for DDH known or believed } \\
\text { to restrict movement, and } \\
\text { reduced movements in DDH } \\
\text { cases reported based on } \\
\text { maternal testimony (see text } \\
\text { for references). Objective } \\
\text { measurement of FM } \\
\text { needed to provide evidence } \\
\text { for relationship between } \\
\text { movement and DDH }\end{array}$ & $\begin{array}{l}\text { a) Myogenic/connective tissue pathology } \\
=>\text { abnormal movements => early-onset } \\
\text { DDH } \\
\text { b) Environmental factors => restricted } \\
\text { movements => DDH } \\
\text { c) Unknown causes => abnormal movements } \\
\text { d) DDH } \\
\text { d) Genetic causes => DDH }\end{array}$ \\
\hline
\end{tabular}

the earliest described time of abnormal movements being between 11 to $16 \mathrm{GW}$ (Donker et al., 2009; Kirkinen et al., 1987), and the latest at 28 to $30 \mathrm{GW}$ (Donker et al., 2009; Mulder et al., 2001). The most common movement profiles for FADS are the complete absence of movement (Kirkinen et al., 1987; Nemec et al., 2011; Paladini et al., 2001; Sherer et al., 1992), and reduced movement (Kirkinen et al., 1987; Nemec et al., 2011). However, jerky and monotonous movements (Mulder et al., 2001) and region specific akinesia (Tongsong et al., 2000) have been reported. The most comprehensive analysis to-date on the quantity and quality of foetal movements with FADS is from Donker et al. (2009), who performed multiple sonographic assessments for motility and posture on 14 foetuses affected with FADS. Contractures were always present from $15 \mathrm{GW}$ onwards in the foetuses affected with FADS. There was a significant reduction in the range of different types of specific movement patterns (e.g., startle, isolated arm/leg movement, jaw opening, etc.) exhibited by FADS foetuses as compared to controls. The quality of the movement (variation in amplitude, speed, and complexity of movements) was abnormal in most FADS foetuses, but only half showed quantitatively less motor activity (time spent moving) than controls. There were no FADS foetuses in which contractures were present and all three movement parameters (quantity, quality and differentiation) were characterised as being normal, although one foetus at $28 \mathrm{GW}$ had contractures of the legs and normal movement differentiation and quality, the quantity of movement not having been assessed in that particular scan. One foetus exhibited an abnormal quantity of movement (at $13 \mathrm{GW}$ ), prior to development of contractures, which were present by $15 \mathrm{GW}$ (Donker et al., 2009).

\section{Risk factors}

The most likely cause-effect relationship for FADS is as follows: a root cause leads to an aberration from normal foetal movement patterns, and the resultant reduced, abnormal or absent movements lead to joint contractures, craniofacial abnormalities and pulmonary hypoplasia. However, it is not possible to discount the hypothesis that, in some cases, contractures could occur first and prevent normal movements, since contractures and (some form of) abnormality of movement are almost always identified together (Donker et al., 2009). Severely abnormal or absent foetal movements can result from muscular or neural conditions, such as myotonic dystrophy or central nervous system anomalies, restrictive dermopathy (a lethal autosomal recessive skin condition), teratogen exposure, intrauterine ischemia, or unknown causes (Hall, 2009; Witters et al., 2002; Yfantis et al., 2002). While restricted intrauterine space due to factors such as multiple pregnancy, uterine abnormalities or oligohydramnios, may reduce foetal movements, it is unlikely that space limitation alone will lead to the lethal form of FADS (Hall, 2009). In cases in which a neuromuscular disorder is present, FADS has been proposed to be the severe end of the spectrum of disease entities such as spinal muscular atrophy and congenital muscular dystrophies and myopathies (Ravenscroft et al., 2011), with foetal 
akinesia potentially resulting from a recessive rather than a dominant trait (Ravenscroft et al., 2011). At least 20 familial types of FADS have been identified, as reviewed by Hall (2009), and a number of genes associated with foetal akinesia have been identified (Ravenscroft et al., 2011). However, for the majority of cases of FADS, no specific diagnosis can be made (Witters et al., 2002). Next generation sequencing of cohorts of characterised cases of FADS has been highlighted as a promising way forward to improve diagnosis of foetal akinesia and to help inform genetic counselling and to facilitate prenatal diagnoses (Ravenscroft et al., 2011).

\section{Diagnosis and treatment}

Most cases die in utero, at birth or in the newborn period because of severe pulmonary hypoplasia (Hall, 2009). FADS is usually detectable in a prenatal ultrasound, with the most consistent early indication being joint contractures (Donker et al., 2009). Foetal MRI (Nemec et al., 2011) and 4-D ultrasound (Ruano et al., 2003) have been proposed as adjuncts to prenatal ultrasound for confirming, and possibly advancing upon, the ultrasound diagnosis. When FADS is diagnosed prenatally, the foetus is often terminated due to the very low or non-existent chance of survival.

\section{Animal models}

FADS is not a true diagnosis or specific syndrome, but rather a group of abnormalities that lead to foetal akinesia. A number of animal model systems in which prenatal movements have been eliminated have replicated the major features of FADS; including joint contractures, spinal abnormalities and pulmonary hypoplasia. A study in which rat foetuses were paralysed in utero in the last 3 days of development using a neuromuscular blocking agent, led to similar symptoms to those seen in human infants (Moessinger, 1983), and was instrumental in determining that FADS is a syndrome related to the absence of foetal movement rather than a specific condition. Genetically modified mouse lines in which skeletal muscle is absent or non-functional (Kahn et al., 2009; Nowlan et al., 2010a; Pai, 1965; Rot-Nikcevic et al., 2006) and pharmacologically immobilised chick model systems (Drachman and Sokóloff, 1966; Hall and Herring, 1990; Hosseini and Hogg, 1991; Murray and Drachman, 1969) can also replicate the main symptoms of FADS.

\section{Arthogryposis}

\section{Aetiology}

Arthrogryposis, or multiple congenital contractures, is also a syndrome with the common root cause of reduced foetal movement due to abnormal muscle and/or neural development. The term is used to describe patients in whom joints in two or more body parts are abnormally angled or bent. The condition is relatively rare, with an estimated incidence of between 1:3000 and 1:5000 (Lowry et al., 2010). Arthrogryposis is a clinical finding rather than a specific diagnosis, and is a feature of more than 300 different disorders (Bamshad et al., 2009; Filges and Hall, 2013). There are two broad types of arthrogryposis based on whether the newborn child has normal neurological function. An abnormal neurological examination indicates abnormalities of the central nervous system (CNS) or the neuromuscular system, where the abnormalities are due to dysgenesis (curtailment or disruption of the program of development, e.g., of the anterior horns of the spinal cord and motor nuclei of brainstem) or degeneration (e.g., spinal muscular atrophy) or both (Banker, 1986). These abnormalities are the most common causes of severe arthrogryposis (Bamshad et al., 2009). When normal neurological function is present, the arthrogryposis is likely to be due to a connective tissue disorder, amyoplasia, foetal crowding, or so-called distal arthrogryposis (Bamshad et al., 2009). Amyoplasia (lack of muscle growth) is a sporadic condition where limb muscles are partly or fully replaced by fatty-fibrous tissues (Hall et al., 2014), and is the most prevalent type of arthrogryposis, accounting for a third of all cases (Filges and Hall, 2013). The most common presentation of amyoplasia at birth is symmetric involvement of all four limbs with internally rotated shoulders, extended and pronated elbows, flexed wrists, stiff fingers with the thumbs positioned in the palm, dislocated hips, extended knees and severe equinovarus contractures (club foot) (Bamshad et al., 2009), as shown in Fig. 3. The aetiology and pathogenesis of amyoplasia is unknown, but vascular compromise of the developing spinal cord leading to interruption of maturation of

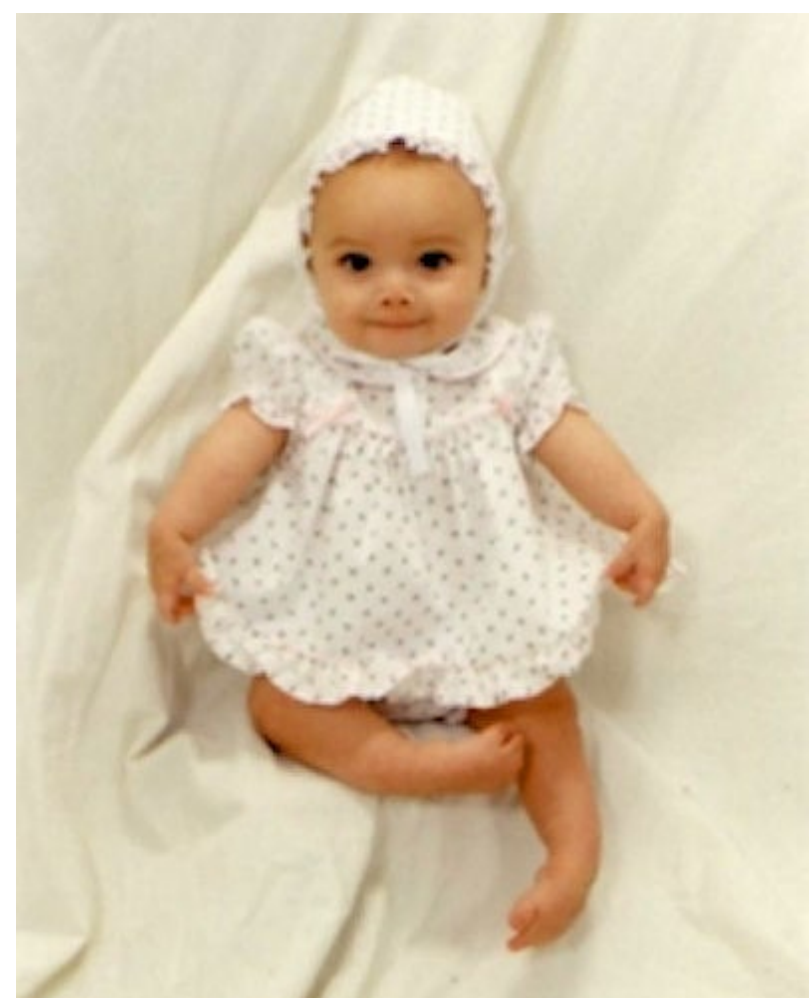

Fig. 3. Child with amyoplasia with (not quite symmetric in this case) involvement of all four limbs, internally rotated shoulders, extended and pronated elbows, flexed wrists, stiff fingers with the thumbs positioned in the palm, extended knees and equinovarus contractures. Reproduced with permission (C) Ani Samargian. 
anterior horn cells (motor neurons of the axial muscles) and interruption of the development of the related limb muscles has been suggested as a hypothesis regarding aetiology (Hall et al., 2014). Distal arthrogryposes are a group of autosomal dominant disorders that involve the hands and feet with the larger joints normally spared. Ten different types of distal arthrogryposes have been described to date, which are classified hierarchically according to the key diagnostic criteria (Bamshad et al., 2009). The most common of the distal arthrogryposes is thought to be distal arthrogryposis type 2, which is also known as SheldonHall syndrome (Bamshad et al., 2009). Key features of the condition (in addition to contractures of the hands and feet) include scoliosis, a very small mouth and puckered lips (Bamshad et al., 2009).

Despite wide acceptance that abnormal foetal movements are inherent to arthrogryposis, a clear picture on the patterns and quantity of foetal movements in affected foetuses does not currently exist. However, it is highly likely that the heterogeneous nature of the syndrome would also lead to a range of effects on foetal movements between different patients. Two sources of information available on foetal movements in foetuses with arthrogryposis are case reports and retrospective reports of maternal sensation. Reports of maternal sensation of foetal movements in cases of arthrogryposis describe maternal sensation of both decreased and increased foetal movements. Hall et al. (1983) report that decreased movements were noticed in 26 out of 79 pregnancies with an affected foetus, and increased movements in 5 of those pregnancies. Wynne-Davies and Lloyd-Roberts (1976) reported similar findings, with 25 out of 66 mothers of children with arthrogryposis reporting decreased or absent foetal movements and 7 reporting increased movements. However, maternal testimonies taken after the birth of an affected child (and particularly when the testimony is taken years after the birth) cannot be assumed to be reliable, and furthermore, maternal sensation of foetal movement is subjective (Hertogs et al., 1979). Quantification of movement using ultrasound for foetuses affected by arthrogryposis has been performed in only a very small number of arthrogryposis foetuses, with all studies reporting abnormal or absent movement during the period of imaging. The absence of movement in foetuses with arthrogryposis has been reported for scans performed at $19 \mathrm{GW}$ (Baty et al., 1988; Sepulveda et al., 1995), 23 GW (Baty et al., 1988), and 30.5 GW (Goldberg et al., 1986). Dudkiewicz et al. (1999) describe a case of distal arthrogryposis type 1 , in which the hands and fingers were immobile throughout an ultrasound examination at $23 \mathrm{GW}$, while there was normal movement of the lower extremities. When the child was born, only the hands and fingers were affected (Dudkiewicz et al., 1999). Only one of the movement quantification studies described above examined the same foetus at more than one time point (Baty et al., 1988), and no ultrasound studies examined more than one foetus with arthrogryposis. It is clear that more real-time ultrasound studies of affected foetuses from across the spectrum of the arthrogryposis syndrome, and at a range of stages of gestation, are needed in order to better facilitate diagnosis and clinical understanding of the condition.

\section{Risk factors}

When disorders of the nervous system, neuromuscular system or connective tissues lead to arthrogryposis, there is usually a genetic origin, with a high degree of heredity (Filges and Hall, 2013). A list of the most frequent mutations leading to arthrogryposis is provided in Filges and Hall's paper from 2013. For example, the distal arthrogryposes are autosomal dominant disorders, and genetic mutations that can cause distal arthrogryposis have been identified in genes involved in encoding components of fast-twitch myofibres (Bamshad et al., 2009). Non-genetic risk factors for arthrogryposis include foetal overcrowding (Hall et al., 1983), maternal illness (e.g., multiple sclerosis, myasthenia gravis (Bevan et al., 2007)), or drug consumption (e.g., treatment for tetanus (Jago, 1970)). The condition has an increased prevalence in twins, and in pregnancies in which environmental conditions restrict foetal movements, such as in the case of a bicornate uterus or with oligohydramnios (Hall et al., 1983). However, amyoplasia, the most common form of arthrogryposis, is apparently completely sporadic (Hall et al., 2014) with monozygotic twins discordantly affected (Hall et al., 1983), and the risk factors are as yet unknown. In cases of arthrogryposis with a neurogenic, myogenic or connective tissue pathology, or the presence of a maternal muscular condition or maternal drug use, it is highly likely that the cause-effect relationship is that the reduced or abnormal movements lead to joint contractures. However, it is not currently possible to define the causeeffect relationship in amyoplasia and in other sporadic incidents of arthrogryposis, and it is likely that there could be different causal pathways between different types and incidences of the syndrome. A number of hypothesised causal pathways are proposed in Table 1 , but it is indisputable that there needs to be a much more extensive and in-depth analysis of posture and motor assessment in a large number of foetuses with arthrogryposis (similar to the type of study performed by Donker et al. (2009) for FADS, ideally with an increased sample size) in order to gain a better insight into the root causes of the syndrome.

\section{Diagnosis and treatment}

Treatment for multiple congenital contractures involves a combination of casting and splinting, physical therapy and surgical reductions and soft tissue release, with the main goal being towards improving patient independence, particularly for communication, activities of daily life and mobility (Bevan et al., 2007). There is a very low rate of prenatal diagnosis for multiple congenital contractures, with only $22.2 \%$ of 107 cases being diagnosed prenatally (Filges and Hall, 2013). Filges and Hall (2013) highlight the lack of established standards for quantifying foetal movements, and point out that prenatal diagnosis of amyoplasia could enable potential interventions to improve the child's prognosis, such as increasing foetal movement (e.g., with caffeine or maternal exercise (Hall et al., 2014)) or prompting early delivery.

\section{Animal models}

Animal models for specific genetic conditions leading to arthrogryposis have been proposed (Ha et al., 2013), as have model systems replicating the effects of maternal 
conditions (Jacobson et al., 1998). Arthrogryposis in agricultural animals has been shown to occur when toxic alkaloids are ingested by the pregnant mother, or when the Akabane virus is contracted during the pregnancy (Swinyard and Bleck, 1985). No model system has been proposed for the hypothesised link between vascular compromise of the placenta and amyoplasia. A range of model systems of abnormal prenatal movement (as outlined above for FADS) replicate the end result of joint contractures common to all conditions leading to arthrogryposis, but the only study that has studied the development of joint contractures in significant detail is from Drachman and Coulombre (1962). Chick embryos were temporarily immobilised for between $24-48 \mathrm{~h}$, at a range of time periods between 7-15 days of incubation, and then grown to the full incubation period of 21 days. Although movement gradually resumed in the foetal chicks after the end of the immobilisation period, limb deformities were present at hatching, with the more advanced degrees of deformity being associated with higher concentrations of neuromuscular blocking agent and with older ages for initiation of treatment. The authors describe how the survivors developed an adaptive gait to their persistent deformities. It is significant that a brief period of immobilisation (less than $10 \%$ of the incubation period) caused such a permanent deformity (Drachman and Coulombre, 1962).

\section{Developmental Dysplasia or Dislocation of the Hip (DDH)}

\section{Aetiology}

DDH occurs when the joint between the femoral head and the acetabulum is unstable or malformed, or when the femoral head is partially or completely dislocated from the acetabular cup (Aronsson et al., 1994; Weinstein, 1987). The condition includes hips that are unstable, partially or fully dislocated, or malformed (American Academy of Pediatrics, 2000), as shown in Fig. 4. Instability in a hip is present when a tight fit between the femoral head and the acetabulum is absent, leading to abnormal movement of the femoral head, while a dislocation is defined as a loss of contact between the femoral head and the acetabulum (American Academy of Pediatrics, 2000). While it was initially believed that primary acetabular dysplasia would lead to DDH (Aronsson et al., 1994), it has been shown in animal models that acetabular dysplasia develops when the femoral head is not concentrically reduced in the acetabulum, and can be reversed by restoring a normal relationship between the two bones (Salter, 1968). Two types of dislocation have been defined (Aronsson et al., 1994); paralytic dislocations, which initiate during the first or second trimester and are often associated with neuromuscular disorders or genetic defects, and typical dislocations, which occur in otherwise healthy infants and may occur in utero, at birth or after birth. The incidence of persistent and clinically diagnosed hip dysplasia has been calculated to be 1.3 per 1000 (Leck, 2000), with higher prevalence of neonatal clinical hip instability of 11.5 per 1000 detected through orthopaedic screening (American

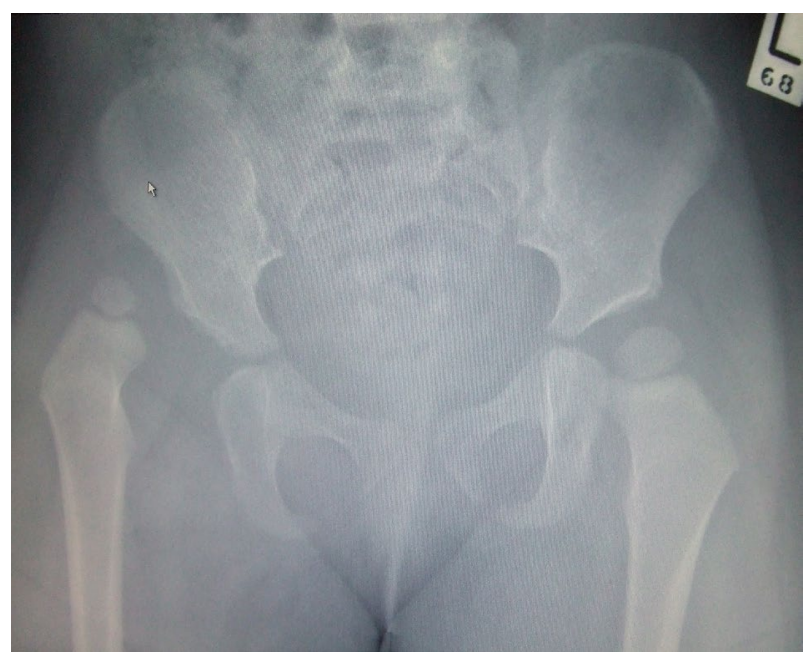

Fig. 4. Developmental dysplasia of the right hip in a young child of estimated age 2.5 years (Image: http:// en.wikipedia.org/wiki/File:Dislocated_hip.jpg).

Academy of Pediatrics, 2000). Some ethnicities and/ or geographical regions have higher incidence rates of DDH than the general population, such as the Japanese (Yamamuro and Ishida, 1984) and Northern Italian (Riboni et al., 2003) populations. Many detected cases of hip instability in newborns resolve without any medical intervention (Bialik et al., 1999), but if dysplasia persists and is undetected or untreated, severe osteoarthritis can develop (Wedge and Wasylenko, 1979).

\section{Risk factors}

DDH is a multifactorial disease, with both genetics and environment thought to play a role. Genetic risk factors include female gender (Chan et al., 1997) and positive family history (Stevenson et al., 2009; Wynne-Davies, 1970). It is thought that female babies are at higher risk due to their susceptibility to the maternal hormone relaxin, which may contribute to ligamentous laxity in the hip joint (Maclennan and Maclennan, 1997). There is limited information on what genes may be responsible for the familial incidence of DDH, with most studies proposing an association between a genetic or chromosome variant and DDH being focussed on individual families or single ethnicities (Dai et al., 2008; Feldman et al., 2010; Feldman et al., 2012; Hao et al., 2014; Rouault et al., 2010; Tian et al., 2012), limiting their impact on the wider population. However, evidence that GDF-5 may be linked with DDH has been revealed for both Chinese Han (Dai et al., 2008) and western Brittany (Rouault et al., 2010) patient groups. Intriguingly, abnormal GDF-5 expression has been shown in the elbow joints of immobile "muscleless limbs" mouse embryos (Kahn et al., 2009), which undergo aberrant shape morphogenesis (Kahn et al., 2009; Nowlan et al., 2010a). Based on the in vivo mechanosensitivity of GDF5 (Kahn et al., 2009), could a GDF-5 single nucleotide polymorphism (SNP) affect the mechano-response of the joint tissues to foetal movements? Furthermore, GDF-5 has been identified as a susceptibility gene for hip osteoarthritis (Chapman et al., 2008; Evangelou et al., 2009; Miyamoto et al., 2007; Southam et al., 2007; Vaes et al., 2009). 
Considering the increased risk of hip osteoarthritis in later life for patients with undiagnosed or unsuccessfully treated hip or acetabular dysplasia (Engesæter et al., 2008; Reijman et al., 2005; Sandell, 2012), the role of GDF-5 certainly offers a fascinating line of enquiry for the future.

Even in families with a predisposition to $\mathrm{DDH}$, the mechanical environment is also of key importance for hip development (Stevenson et al., 2009). Risk factors for DDH relating to the mechanical environment and/or foetal movement patterns include; foetal breech position, in which movement of the hips is limited, (Muller and Seddon, 1953); first born, reputedly due to high uterine tone (Wilkinson, 1963); large babies (Hinderaker et al., 1994); oligohydramnios (Hinderaker et al., 1994); and congenital neuromuscular problems (American Academy of Pediatrics, 2000; Iwahara and Ikeda, 1962). Neonatal hip instability is more than four times more frequent in breech presentations (Hinderaker et al., 1994), with extended breech leading to the highest risk of DDH (Holen et al., 1996). The left hip is more commonly affected than the right hip in non-breech newborns (Aronsson et al., 1994), and it has been proposed that this is due to limited abduction of the left hip due to the common positioning of the left leg beside the mother's spine (Aronsson et al., 1994). Postnatal positioning of the thighs in extension and adduction, using cradle boards in Native American populations or tight swaddling in Japan, can increase the risk of dysplasia in the hips developing post-natally (Dezateux and Rosendahl, 2007; Salter, 1968; Yamamuro and Ishida, 1984). Interestingly, twins do not exhibit higher rates of DDH than singleton births (De Pellegrin and Moharamzadeh, 2010; Doyle et al., 1991), despite the restricted environment of the uterus and the increased likelihood of breech presentation of at least one twin. Twins normally have flexed knees, which is suggested to be protective for DDH (De Pellegrin and Moharamzadeh, 2010). Additionally, twins are normally of a lower average weight at birth than singletons, and high birth weight is a further risk factor for hip dysplasia (De Pellegrin and Moharamzadeh, 2010).

A number of hypothesised causal pathways leading to DDH are proposed in Table 1. Despite the list of factors relating to an abnormal or restricted intra-uterine mechanical environment associated with DDH, I am not aware of any case report or cohort study in which foetal movement was characterised in a foetus that was later diagnosed with DDH. Therefore, while it is hypothesised that most cases of early-onset DDH are due to a muscle or connective tissue pathology, and that environmental factors leading to reduced movements play a role in typical (late-onset) DDH, these hypotheses cannot be corroborated without serial assessments of foetal movements in DDH cases for comparison with normal controls. Such a study is unlikely to be feasible using clinical imaging methods, due to the fact that DDH cannot currently be diagnosed prenatally (unlike FADS and arthrogryposis in which contractures are present), and so it would be impossible to identify subjects for prospective repeated sonographic assessments. If a non-invasive, wearable sensor for foetal movements were available (Nishihara et al., 2008; Ryo et al., 2012), a study could be performed in which foetal movements would be regularly monitored in a large cohort (ideally including foetuses at higher risk of DDH due to foetal breech position or family history), over the course of the second and third trimesters, and foetal movement patterns later compared between cases diagnosed postnatally with $\mathrm{DDH}$ and normal controls. In this way, the importance of quantity or quality of movements at specific timepoints or over extended periods of gestation for healthy hip development could be explored.

\section{Diagnosis and treatment}

Newborn infants are tested for hip stability using one or both standardised manipulation tests known as the Barlow and Ortolani manoeuvres (Barlow, 1962; Ortolani, 1937). Some countries have introduced ultrasound screening for at-risk infants (Lowry et al., 2005), but routine ultrasound screening of infants is not recommended, due to the high cost of such blanket screening methods, and the potential for overtreatment or unnecessary interventions (Dezateux and Rosendahl, 2007; American Academy of Pediatrics, 2000). The lack of randomised control trials for both screening and treatment for DDH have been highlighted repeatedly (Dezateux and Rosendahl, 2007; American Academy of Pediatrics, 2000). When DDH is diagnosed early (prior to 6 months of age), a splinting device, such as the Pavlic harness (Pavlik, 1992), is used to guide the hips into flexion and abduction to obtain concentric reduction of the hip (Aronsson et al., 1994). If splinting is unsuccessful or if DDH is diagnosed after 6 months, surgical procedures including closed reductions and (in severe cases) open reductions, combined with a spica cast, are recommended (Pavlik, 1992). Late detection of DDH is a significant problem, and even when a screening programme is in place, it is likely that 1 in 5000 children will have a dislocated hip detected at 18 months of age or older (Dezateux and Godward, 1996). Complications of splinting include femoral nerve palsies, pressure sores, difficulties in handling the baby, and parental anxiety (Dezateux and Rosendahl, 2007). However, the most serious complication of treatment is iatrogenic osteonecrosis of the femoral head, also referred to as avascular or aseptic necrosis of the femoral head, which has a frequency from 5-60\% after surgical treatments and from $0-14 \%$ after non-surgical treatments (Dezateux and Rosendahl, 2007). Osteonecrosis occurs when the blood supply to the femoral head is interrupted and results in tissue morbidity and abnormal hip development (American Academy of Pediatrics, 2000). Studies have suggested that the presence of the secondary centre of ossification in the proximal femur prior to reduction decreases the risk of osteonecrosis (Segal et al., 1999a) due to the increased mechanical stiffness of the capital femoral epiphysis when the ossific nucleus is present (Segal et al., 1999b), but a meta-analysis of six observational studies did not find a significant effect of the presence or absence of the ossific nucleus on the development of osteonecrosis (Roposch et al., 2009). Patients treated for DDH are thought to be at increased risk of developing early hip osteoarthritis, particularly those children who undergo a closed or open reduction. In a follow-up study of $264 \mathrm{DDH}$ patients, more than half of the patients had radiological signs of 
osteoarthritis, with $30 \%$ of patients experiencing pain (Muller and Seddon, 1953). Of the patients experiencing pain, $87 \%$ of these reported an age of onset of pain of 40 or younger (Muller and Seddon, 1953). As the patients in the above study were treated before 1940, it is debatable how much relevance these statistics have for patients treated today. However, it has recently been proposed that joint shape is a key determinant in the risk of osteoarthritis (Hogervorst et al., 2012; Sandell, 2012), which may therefore mean that DDH patients in whom an "optimal" joint shape was not achieved (not necessarily equivalent to the treatment aim of a stable joint shape) may be at increased risk of developing osteoarthritis in later life.

\section{Animal models}

Historically, the most commonly used model system for DDH was canine hip dysplasia $(\mathrm{CDH})$. Canine hip dysplasia has been defined as a biomechanical disease where hip instability leads to altered forces in the growing femoral head and acetabulum (Fries and Remedios, 1995). The frequency of the disease varies between breeds, with heavier, larger, and faster-growing dogs being more susceptible (Riser et al., 1985). However, key differences between CDH and DDH mean that dogs are not an appropriate model system for investigating the aetiology of human hip dysplasia. Firstly, in contrast to $\mathrm{DDH}, \mathrm{CDH}$ is never present at birth (Fries and Remedios, 1995), and secondly, subluxation in dogs does not occur until the dogs begin weight-bearing (Fries and Remedios, 1995), whilst DDH develops in very early life and prior to any crawling or walking. The young rabbit has also been used as an experimental model system for DDH (Langenskiöld et al., 1962; Michelsson and Langenskiöld, 1972; Wilkinson, 1963). In recent years, two new animal models of DDH have been proposed. The first model system reproduces the type of hip dysplasia induced by straight leg swaddling, where the hind limbs of neonatal rats were fixed together in hip adduction and extension with the knees in extension using surgical tape (Wang et al., 2012). The study revealed that prolonged swaddling (first ten neonatal days) led to the highest rate of hip dysplasia (82\%) with high rates of dislocation, followed in severity by early swaddling (first 5 days, $48 \%$ dislocated or dysplastic) with only $20 \%$ abnormal hips in the late swaddling group (neonatal days 6-10). The same model system was adopted by another group, who investigated changes in chondrocyte differentiation in swaddlinginduced hip dysplasia (Pei et al., 2014). Our group recently proposed the immobilised chick embryo as a model system for early-onset (teratological or "paralytic") dislocations which result from neuromuscular disorders (Nowlan et al., 2014). Chick embryos were immobilised by in ovo administration of a neuromuscular blocking agent at day 4 of incubation, prior to the commencement of any spontaneous limbs movements. As expected based on previous studies (reviewed in Nowlan et al., 2010b), joint cavitation did not occur in the immobilised hip joints. However, our study revealed for the first time that hip joint shape morphogenesis was dramatically affected by the absence of movements only after the time point at which joint cavitation should have occurred. Effects on the immobilised joints included flattening of the proximal femur, abnormal orientation of the femur with the pelvis, and abnormal coverage of the acetabulum (Nowlan et al., 2014). Experiments are underway to investigate the critical time points for foetal movements' influence on hip abnormalities, and also to investigate if the foetal hip joint can recover if movement is enabled after a period of immobilisation.

\section{Susceptibility}

The adult hip joint is one of the most stable joints in the body, and it is curious that it is the only joint to be routinely and non-traumatically dislocated or dysplastic at, or soon after, birth. It is interesting to note that the acetabulum is at its deepest (in shape) very early in development (first trimester), and becomes gradually more shallow until the time of birth (Ráliš and McKibbin, 1973). After birth, the trend reverses and the acetabulum becomes deeper as the child grows (Ráliš and McKibbin, 1973). The shape of the femoral head also undergoes changes in shape that affect stability. From an almost globular shape in early development, the femoral head becomes more and more hemispherical approaching birth, while after birth a more globular shape begins to develop (although it never attains the almost perfectly spherical shape of early development) (Ráliš and McKibbin, 1973). The combination of these shape changes mean that the coverage of the femoral head by the acetabulum is lowest at birth compared to any other timepoint in development, childhood or adulthood (Ráliš and McKibbin, 1973). Could it be that hip dysplasia is an extreme outcome of the normal developmental process of increasing acetabular shallowness and decreasing coverage of the femoral head? Perhaps this process of increasing shallowness is mediated by movements at the hip joint, and accelerated when movements are restricted, leading to instability or, in extreme cases, dislocation. These research questions offer potential avenues for providing new insights into the aetiology of DDH.

\section{Bone Disease of Prematurity}

Bone disease of prematurity (also known as osteopenia of prematurity) is a complication of prematurity which leads to bone softening and fractures. It occurs in up to $30 \%$ of severely preterm infants (those born at less than 28 weeks of gestation) (Sharp, 2007). Infants born prematurely miss some of the most active period of active bone mineralisation in the third trimester, which leads to deficits in both nutritional and biomechanical factors affecting bone. Nutritionally, preterm infants do not receive as much of the calcium and phosphorus that is transported across the placenta during the last trimester of pregnancy as compared to that received by a full term infant (Sharp, 2007). Preterm infants also miss a critical period of biomechanical stimulation, as foetal movements in the restricted mechanical environment of the late stage pregnancy are likely to induce high stresses and strains in the foetal bones. Sharpe (2007) proposed that the significant period of mechanical stimulation from 'resistance training' against the uterine wall during late 


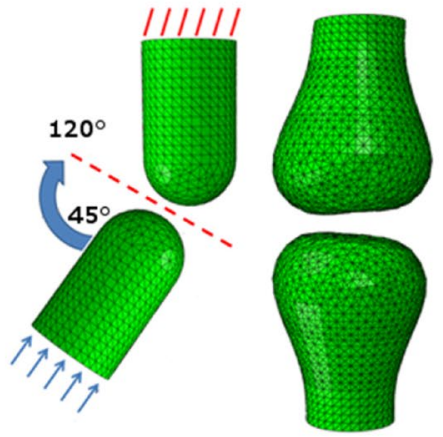

Hinge Movement
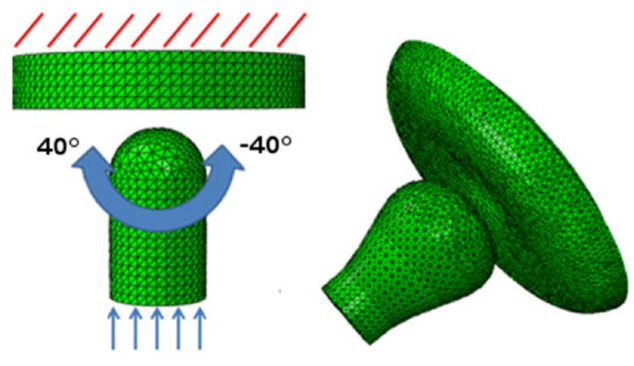

Rotational Movement

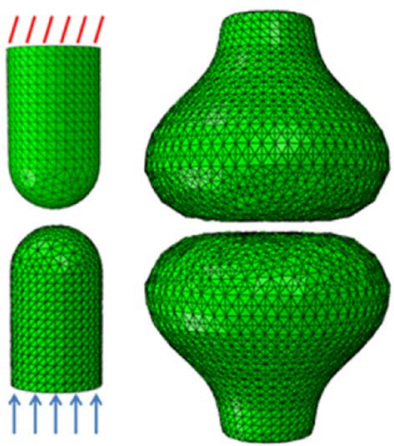

No Movement

Fig. 5. 3-D mechanobiological models of joint shape morphogenesis, where characteristic joint shapes are determined by the type of movement applied. Images from results described in Giorgi et al. (2014).

development could play an important role in building up bone strength before birth. This same theory was addressed by Moyer-Mileur and colleagues, who performed physical therapy on very low birth weight infants, and found that bone area and bone mineral content were significantly greater in infants who underwent the physical therapy program as compared to matched controls who did not receive any physiotherapy (Moyer-Mileur et al., 2000; Moyer-Mileur et al., 1995; Moyer Mileur et al., 2008). Similar results for a positive effect of physical therapy on bone strength (Litmanovitz et al., 2003) and of physical therapy plus massage on a bone formation marker (Aly et $a l ., 2004$ ) have been found in small studies, but large-scale trials of such therapies are lacking.

\section{Biomechanical Analyses of Foetal Environment and Movements}

\section{Computer models of foetal biomechanics}

The influence of several aspects of the birthing process on the musculoskeletal system have been modelled, such as foetal head moulding (Lapeer and Prager, 2001; McPherson and Kriewall, 1980a), shoulder dystocia (Gonik et al., 2003a; Gonik et al., 2003b), and the maternal pelvic floor muscles (Martins et al., 2007; Parente et al., 2008). However, only a very small number of studies have used computational models of human prenatal movement to predict the effects on skeletal development. Obtaining accurate morphologies of healthy human foetal skeletons is usually not possible, and therefore all of the models described herein use representative or idealised shapes.

Carter and Wong (1988) predicted the effects of a range of loading histories on endochondral ossification of the secondary ossification centre and the epiphyseal growth plate, using two-dimensional finite element models of the chondroepiphysis. Shefelbine and Carter (2004) used a mechanobiological model to compare the effects of normal and abnormal foetal ranges of hip motion on development of the epiphyseal ossification front and likelihood of coxa valga in DDH. Heegaard et al. (1999) proposed the first mechanobiological model of finger joint morphogenesis, where movement of the joint promoted formation of a locally concave-convex surface. Research from our group (Giorgi et al., 2014) implemented three dimensional mechanobiological models of dynamic joint shape morphogenesis, demonstrating that when cartilage growth is influenced by biomechanical factors, the type of loading regime applied determines the development of characteristic joint shapes, as shown in Fig. 5.

In contrast to human studies, it is feasible to obtain 3D morphologies for the skeletal rudiments of animal developmental model systems for biomechanical modelling. Combining novel 3D imaging of embryonic specimens, using optical projection tomography (Sharpe et al., 2002), with finite element analysis enabled our group to model the effects of foetal movement on the initiation and progression of primary ossification centres (Nowlan et al., 2008a) and to correlate patterns of biomechanical stimuli with mechanosensitive gene expression patterns for mobile and immobile chick embryos (Nowlan et al., 2008b). By quantifying the biomechanical stimuli induced by active and passive movements in foetal mouse limbs using finite element analysis, we developed a new theory relating to the role of passive movements in skeletal development when spontaneous movements are absent (Nowlan et al., 2012). The same methods have also been used to characterise patterns of biomechanical stimuli in the foetal chick joint, revealing that biomechanical stimuli colocalise with regions of growth and elevated proliferation (Roddy et al., 2011a) and that changes in joint shape and proliferation induced by immobilisation are accompanied by region-specific changes in biomechanical stimuli in the joint (Roddy et al., 2011b).

\section{Material Properties of Foetal Tissues and Environments}

\section{Musculoskeletal tissue properties}

Accurate material properties are essential for building more realistic and representative models of human foetal movement, and for gaining a better understanding of how passive deformation of cartilaginous joints could occur. 
Mechanical properties of animal foetal skeletal tissues have been discussed previously (Nowlan et al., 2007) but properties for human tissue are less well described. While it is feasible to obtain maternal tissues, such as uterine tissue after maternal surgery, or tissues associated with the foetus, such as amnion and placenta, after birth, obtaining material properties of human foetal skeletal tissues is highly challenging due to ethical and moral issues. Therefore, there are only a very small number of studies of foetal skeletal tissues. Mahmoodian et al. (2009) reported that the talar cartilage of two foetuses between 30-32 weeks had a stiffness (aggregate modulus of $150 \mathrm{kPa}$ ) an order of magnitude lower than that of adult articular cartilage and permeability $\left(2.01 \times 10^{-14} \mathrm{~m}^{4} \mathrm{~N}^{-1} \mathrm{~s}^{-1}\right)$ an order of magnitude greater than adult cartilage, suggesting that foetal cartilage is likely to deform and relax to larger extents than adult cartilage. In a follow-up study, Mahmoodian et al. (2011) tested the mechanical properties of seven foetal talus anlagen over a range of gestational ages between 20 and 36 gestational weeks, and found that stiffness increased by a factor of roughly 2.5 (from 59.9 to $148 \mathrm{kPa}$ ), and permeability decreased by $20 \%$ (from $2.64 \times 10^{-14}$ to $\left.2.06 \times 10^{-14} \mathrm{~m}^{4} \mathrm{~N}^{-1} \mathrm{~s}^{-1}\right)$ over the age range studied. These changes in mechanical properties were associated with an increase in collagen content and integrity, and a decrease in proteoglycan content (Mahmoodian et al., 2011). A study of the chondroepiphysis of the foetal proximal femur (Brown and Singerman, 1986) reported a much higher equilibrium modulus $(0.699 \mathrm{MPa})$ and much lower values for permeability $\left(0.251 \times 10^{-14} \mathrm{~m}^{4} \mathrm{~N}^{-1} \mathrm{~s}^{-1}\right)$ and Poisson's ratio than the aforementioned foetal talus studies (Mahmoodian et al., 2009; 2011), which could reflect either differences in experimental design, differences between the properties of the two rudiments, or a combination of these factors. McPherson and Kriewall (1980b) performed three-point bending tests on foetal cranial bone, and found that the elastic moduli of the ossified specimens oriented parallel to the grain pattern of the bone increased from an average of $1.65 \times 10^{3} \mathrm{MPa}$ in foetuses from 24-30 gestational weeks to $3.86 \times 10^{3} \mathrm{MPa}$ in foetuses from $36-40$ weeks.

\section{Properties of the foetal environment}

Construction of models of foetal movement will also require an understanding of the properties of the fluid, tissues and structures surrounding the foetus. Of particular importance is the foetal membrane (chorioamnion), which is composed of a stiff and strong inner amnion layer and a cellular outer chorion layer (Oyen et al., 2005). The collagenous amnion is the primary strength bearing layer in the foetal membrane, and has been shown to become weaker at term and further weakened by labour (Oyen et al., 2004; Oyen et al., 2006). Foetal movements may also impinge upon the placenta. The placental organ has maternal and foetal components, the latter of which includes a chorioamnion layer. Placental abruption, the premature rupture of the placenta from the uterus, is a risk of motor vehicle accidents involving pregnant occupants (Manoogian et al., 2008), and the mechanical properties of the placenta have been tested under high strain rates to contribute to computational models of pregnant occupants in such accidents (Hu et al., 2009; Manoogian et al., 2008).
However, foetal movements incur much lower strain rates than a motor vehicle crash, and since the placental tissue is visco-elastic (Hu et al., 2009), these values may not be relevant when low strain rates apply. The volume and distribution of amniotic fluid are also likely to play a key role in facilitating foetal movement. Amniotic fluid is created by the flow of fluid from the foetal lung and bladder, from water that arrived from the maternal circulation across the placenta (Beall et al., 2007a). Amniotic fluid volume increases from approximately $20 \mathrm{~mL}$ at 10 weeks to $770 \mathrm{~mL}$ at 28 weeks and remains relatively constant until week 39 , after which it drops sharply (Brace and Wolf, 1989; Gadd, 1966). The foetus grows in an almost (but not quite) weightless environment, with the decreasing ratio of amniotic to foetal volume likely leading to an decreased buoyancy as term approaches (Makepeace et al., 1931; Wood, 1970). Amniotic fluid pressure increases over gestation (Fisk et al., 1992), and is abnormal in severe cases of abnormal amniotic fluid volume (oligohydramnios or polyhydramnios) (Fisk et al., 1990). However, it is not known if fluid pressure has any direct effects on foetal movements. While the myometrium (uterine smooth muscle) is of key importance to the birthing process, it is unknown how much its properties impact upon the foetus pre-labour, as the amount of external deflection of the foetal membrane by foetal kicks has not been measured. It has been shown that the contractile (Wood, 1964) and dimensional (Gillespie, 1950) properties of the myometrium change over the course of a pregnancy. Research is needed to determine if foetal movements impinge upon the myometrium, or if they are fully constrained within the foetal membrane. If it is revealed that foetal movements do interact with the myometrium, then material properties of the myometrium during pregnancy will be necessary when constructing computational models.

\section{Discussion}

The principal aims of this review were to describe the effects of internal and external stimuli on foetal movements, to discuss the three most common musculoskeletal conditions in which abnormal foetal movements are implicated as a causal factor, and to investigate biomechanical analyses that have been performed on the foetal musculoskeletal system and the intra-uterine environment. In this section, I will summarise what is known and what is unknown in each of these three areas, and discuss ways in which outstanding questions may be answered.

\section{Foetal movements}

We know that foetal movements generally start and differentiate into a wide variety of movement types at very similar time points of prenatal development, and that gross foetal movements are not generally affected by maternal consumption of food, caffeine or alcohol. There is evidence to suggest that there can be substantial variability in total movements and in the quantity of specific movement patterns between foetuses, but we have no information on how variable the minimum and maximum ranges of 
movement frequencies are for healthy foetuses, and no idea why some foetuses move more or less than others. We do not know how the quantity of foetal movement varies according to time of day (despite maternal reports of increased activity in the evening (Minors and Waterhouse, 1979)), or if it varies depending on a range of aspects of maternal lifestyle, e.g., obesity, activity levels and living environment. We know very little of foetal movements in twins and in higher multiples, and it is unclear if gender has an effect on the quantity of foetal movement. We also lack information on foetal movements outside of a clinical monitoring environment, for example during maternal sleep or exercise. Currently, the only way to monitor foetal movements is in a clinical setting using methods such as ultrasound, foetal-MRI and (less reliably) cardiotocograph (CTG). Sensor systems that enable continuous and remote monitoring of foetal movements, such as those proposed by Ryo et al. (2012) and Nishihara et al. (2008), will be needed to determine the normal range of foetal movements during normal maternal activities over development, and will make studies involving large cohorts more feasible and cost-effective.

\section{Musculoskeletal conditions}

Three musculoskeletal conditions for which abnormal foetal movements are implicated as a causal factor have been discussed. FADS is a lethal syndrome in which the main symptoms are multiple joint contractures, pulmonary hypoplasia and thin, weak bones. FADS can result from muscular or neural conditions, restrictive dermopathy, teratogen exposure or intrauterine ischemia, but often, no specific diagnosis can be made. Arthrogryposis, or multiple congenital contractures, is present in patients with joint contractures in two or more body parts. The syndrome is a feature of more than 300 different disorders, and can be caused by neurogenic, myogenic, or connective tissue pathologies, or by environmental factors, maternal illness or unknown factors. Amyoplasia, the most common type of arthrogryposis, is apparently completely sporadic, and the aetiology is unknown. DDH occurs when the hip joint is unstable or dislocated, due to the absence of a tight fit, or a loss of contact, between the femoral head and acetabulum. DDH can initiate early in development, normally due to a neuromuscular disorder or genetic defect, or, more commonly, in the last trimester or after birth, in an otherwise healthy infant with normal neuromuscular function. DDH is a multifactorial condition, with both genetic and environmental factors likely to play a role, but the aetiology is, as yet, unclear. There is some evidence to suggest that infants treated for DDH may be at increased risk of osteoarthritis earlier in life than the rest of the population.

From the extreme situation of FADS, we know that highly abnormal, or completely absent, foetal movements have a severe effect on skeletal development. Of the three conditions discussed in detail in this review, FADS is the only condition for which foetal movement has been relatively well characterised, and we know that a severe decrease or a complete absence of movement occurs in foetuses affected with FADS. The situation is much less clear for arthrogryposis and DDH. For arthrogryposis, there is no objective evidence to suggest that the contractures characteristic of the syndrome can occur in the presence of completely normal movements. However, there have been no detailed descriptions of foetal movement patterns in multiple foetuses with arthrogryposis over several gestational time-points, and therefore, the causal relationship between movements (or change in, or lack thereof) and contractures is unclear. As highlighted by Filges and Hall (2012), most cases of arthrogryposis are not diagnosed prenatally, due to the fact that quantification of foetal movements do not generally form part of standard assessments. Introducing quantification of foetal movements as part of a foetal assessment would likely greatly increase the rate of prenatal diagnosis of arthrogryposis, but will also provide more substantial evidence of the link between movements and contractures. Whilst many of the risk factors associated with DDH are known to be associated with, or cause, reduced or restricted foetal movements, we do not have objective evidence of reduced movements directly leading to hip dysplasia. A key unanswered question applicable to both arthrogryposis and DDH is how much movement is enough to promote normal joint development. Is there a certain frequency, range or amplitude of specific movements which lead to normal joint morphogenesis? Are there particular points in gestation during which foetal movements are more or less critical to development of the bones and joints? Knowledge of this area would provide greater understanding of how and why musculoskeletal conditions related to abnormal foetal movements develop, and could offer enhanced diagnostic and treatment capabilities. A continuous monitoring system for foetal movements, as discussed above, could provide important insights into the complex relationship between foetal movements and normal or abnormal skeletal development. What is also unclear is the mechanobiological mechanisms underlying the effects of foetal movements on skeletal development. More research is needed to untangle the influences of foetal environment, foetal movement and genetics on these conditions.

\section{Biomechanical analyses}

Biomechanical testing has been performed on a number of intra-uterine tissues and structures, but there are limited data for the foetal musculoskeletal tissues over a range of developmental time points. A small number of models of the effects of mechanical forces on long bone ossification and joint morphogenesis have been proposed, but I am unaware of any models which are capable of predicting the magnitudes of biophysical stimuli due to foetal movements in the human foetus. We currently do not know how the two main types of mechanical stimuli induced by foetal movements (stimuli induced directly by muscle contractions and those induced by 'resistance training' against the uterine wall) work together or separately to promote normal skeletal development. Detailed data on the biophysical stimuli acting on the adult human bones and joints (Bergmann et al., 1993; Papini et al., 2007), and in developing animal model systems (Nowlan et al., 2012; Nowlan et al., 2008a), are available, but we have no idea what the equivalent stimuli in the human foetus are. Knowledge of the levels and type of mechanobiological 
stimuli that are induced by foetal movements would be highly valuable, not just in terms of predicting the risk of abnormalities due to position or movement patterns, but also to tissue engineers attempting to recapitulate developmental processes in vitro. If the same biophysical stimuli that are induced by foetal movements could be applied to cartilaginous tissue pre-cursors in culture, this could result in a stronger, more functional cartilage tissue for implantation into damaged adult joints. Ongoing research in our group aims to construct a musculoskeletal model of foetal movements, obtained from cine MRI scans, in order to address these research questions.

In summary, this review has explored the biomechanics of foetal movement, including the effects of physical and other factors on foetal movements, the role of foetal movements in skeletal development, data on the mechanical properties of tissues and structures associated with the foetus, and computational models of foetal movements. The questions outstanding in this field are likely to be answered using non-invasive imaging (e.g., cine MRI and modern ultrasound techniques), sensor systems that enable continuous and remote monitoring of foetal movements, and computational simulations of human foetal movement. The potential benefits of increased investigation into the biomechanics of foetal movement are manifold, and apply to diverse fields including paediatric medicine, developmental biology, tissue engineering and musculoskeletal biomechanics.

\section{Acknowledgements}

The author is grateful to Dr Michelle Oyen, Mr Andreas Roposch and Dr Sandra Shefelbine for their helpful comments and critical review of the manuscript. The reviewers provided in-depth and thorough reviews and their comments and suggestions were most valuable in improving the manuscript. Funding from the European Research Council under the European Union's Seventh Framework Programme (ERC Grant agreement $n^{\circ}$ [336306]) is acknowledged. I wish to confirm that there are no known conflicts of interest associated with this publication and there has been no significant financial support for this work that could have influenced its outcome.

\section{References}

Almli CR, Ball RH, Wheeler ME (2001) Human fetal and neonatal movement patterns: Gender differences and fetal-to-neonatal continuity. Dev Psychobiol 38: 252-273.

Aly H, Moustafa MF, Hassanein SM, Massaro AN, Amer HA, Patel K (2004) Physical activity combined with massage improves bone mineralization in premature infants: a randomized trial. J Perinatol 24: 305-309.

Arduini D, Rizzo G, Giorlandino C, Valensise H, Dell'Acqua S, Romanini C (1986) The development of fetal behavioural states: a longitudinal study. Prenat Diagn 6: $117-124$
Aronsson D, Goldberg M, Kling Jr T, Roy D (1994) Developmental dysplasia of the hip. Pediatrics 94: 201208.

Bagnall K, Harris P, Jones P (1982) A radiographic study of the longitudinal growth of primary ossification centers in limb long bones of the human fetus. Anat Rec 203: 293-299.

Bamshad M, Van Heest A, Pleasure D (2009) Arthrogryposis: a review and update. J Bone Joint Surg Am 91 Suppl 4: 40-46.

Banker BQ (1986) Arthrogryposis multiplex congenita: spectrum of pathologic changes. Hum Pathol 17: 656-672.

Bardeen CR (1905) Studies of the development of the human skeleton. (A). The development of the lumbar, sacral and coccygeal vertebrae. (B). The curves and the proportionate regional lengths of the spinal column during the first three months of embryonic development. (C). The development of the skeleton of the posterior limb. Am J Anat 4: 265-302.

Bardeen CR, Lewis WH (1901) Development of the limbs, body-wall and back in man. Am J Anat 1: 1-35.

Barlow T (1962) Early diagnosis and treatment of congenital dislocation of the hip. J Bone Joint Surg Br 44: 292-301.

Baschat DAA (2004) Fetal responses to placental insufficiency: an update. BJOG 111: 1031-1041.

Baty BJ, Cubberley D, Morris C, Carey J, Reynolds JF (1988) Prenatal diagnosis of distal arthrogryposis. Am J Med Genet 29: 501-510.

Bayat A, Petersen A, Møller M, Andersen G, Ebbesen F (2009) Incidence of fetal akinesia-hypokinesia deformation sequence: a population-based study. Acta Paediatr 98: 3-4.

Beall M, Van Den Wijngaard J, Van Gemert M, Ross M (2007a) Amniotic fluid water dynamics. Placenta 28: 816-823.

Bergmann G, Graichen F, Rohlmann A (1993) Hip joint loading during walking and running, measured in two patients. J Biomech 26: 969-990.

Bevan WP, Hall JG, Bamshad M, Staheli LT, Jaffe KM, Song K (2007) Arthrogryposis multiplex congenita (amyoplasia): an orthopaedic perspective. J Pediatr Orthop 27: 594-600.

Bialik V, Bialik GM, Blazer S, Sujov P, Wiener F, Berant M (1999) Developmental dysplasia of the hip: a new approach to incidence. Pediatrics 103: 93-99.

Bocking A, Adamson L, Cousin A, Campbell K, Carmichael L, Natale R, Patrick J (1982) Effects of intravenous glucose injections on human fetal breathing movements and gross fetal body movements at 38 to 40 weeks' gestational age. Am J Obstet Gynecol 142: 606-611.

Brace RA, Wolf EJ (1989) Normal amniotic fluid volume changes throughout pregnancy. Am J Obstet Gynecol 161: 382-388.

Brown TD, Singerman RJ (1986) Experimental determination of the linear biphasic constitutive coefficients of human fetal proximal femoral chondroepiphysis. J Biomech 19: 597-605.

Buss C, Davis E, Class Q, Gierczak M, Pattillo C, Glynn L, Sandman C (2009) Maturation of the human fetal startle response: evidence for sex-specific maturation of the human fetus. Early Hum Dev 85: 633-638. 
Carter DR, Wong M (1988) The role of mechanical loading histories in the development of diarthrodial joints. J Orthop Res 6: 804-816.

Chan A, McCaul K, Cundy P, Haan E, Byron-Scott R (1997) Perinatal risk factors for developmental dysplasia of the hip. Arch Dis Child Fetal Neonatal Ed 76: F94-100.

Chapman K, Takahashi A, Meulenbelt I, Watson C, Rodriguez-Lopez J, Egli R, Tsezou A, Malizos KN, Kloppenburg M, Shi D (2008) A meta-analysis of European and Asian cohorts reveals a global role of a functional SNP in the 5' UTR of GDF5 with osteoarthritis susceptibility. Hum Mol Genet 17: 1497-1504.

Dai J, Shi D, Zhu P, Qin J, Ni H, Xu Y, Yao C, Zhu L, Zhu H, Zhao B (2008) Association of a single nucleotide polymorphism in growth differentiate factor 5 with congenital dysplasia of the hip: a case-control study. Arthritis Res Ther 10: R126.

De Pellegrin M, Moharamzadeh D (2010) Developmental dysplasia of the hip in twins: the importance of mechanical factors in the etiology of DDH. J Pediatr Orthop 30: 774-778.

de Vries JIP, Fong BF (2006) Normal fetal motility: an overview. Ultrasound Obstet Gynecol 27: 701-711.

de Vries JI, Visser GH, Prechtl HF (1982) The emergence of fetal behaviour. I. Qualitative aspects. Early Hum Dev 7: 301-322.

de Vries JI, Visser GH, Prechtl HF (1988) The emergence of fetal behaviour. III. Individual differences and consistencies. Early Hum Dev 16: 85-103.

Dezateux C, Godward S (1996) A national survey of screening for congenital dislocation of the hip. Arch Dis Child 74: 445-448.

Dezateux C, Rosendahl K (2007) Developmental dysplasia of the hip. Lancet 369: 1541-1552.

Donker ME, Eijckelhof BH, Tan G, de Vries JI (2009) Serial postural and motor assessment of Fetal Akinesia Deformation Sequence (FADS). Early Hum Dev 85: 785 790.

Doyle P, Beral V, Botting B, Wale C (1991) Congenital malformations in twins in England and Wales. J Epidemiol Community Health 45: 43-48.

Drachman D, Coulombre A (1962) Experimental clubfoot and arthrogryposis multiplex congenita. Lancet 280: 523-526.

Drachman DB, Sokóloff L (1966) The role of movement in embryonic joint formation. Dev Biol 14: 401-420.

Dudkiewicz I, Achiron R, Ganel A (1999) Prenatal diagnosis of distal arthrogryposis type 1. Skeletal Radiol 28: 233-235.

Dutton PJ, Warrander LK, Roberts SA, Bernatavicius G, Byrd LM, Gaze D, Kroll J, Jones RL, Sibley CP, Frøen JF (2012) Predictors of poor perinatal outcome following maternal perception of reduced fetal movements - a prospective cohort study. PLoS One 7: e39784.

Efkarpidis S, Alexopoulos E, Kean L, Liu D, Fay T (2004) Case-control study of factors associated with intrauterine fetal deaths. MedGenMed 6: 53.

Engesæter IØ, Lie SA, Lehmann TG, Furnes O, Vollset SE, Engesæter LB (2008) Neonatal hip instability and risk of total hip replacement in young adulthood. Acta Orthop 79: $321-326$
Evangelou E, Chapman K, Meulenbelt I, Karassa FB, Loughlin J, Carr A, Doherty M, Doherty S, Gómez-Reino JJ, Gonzalez A (2009) Large-scale analysis of association between GDF5 and FRZB variants and osteoarthritis of the hip, knee, and hand. Arthritis Rheum 60: 1710-1721.

Feldman G, Dalsey C, Fertala K, Azimi D, Fortina P, Devoto M, Pacifici M, Parvizi J (2010) Identification of a 4 $\mathrm{Mb}$ region on chromosome 17q21 linked to developmental dysplasia of the hip in one 18-member, multigeneration family. Clin Orthop Relat Res 468: 337-344.

Feldman GJ, Peters CL, Erickson JA, Hozack BA, Jaraha R, Parvizi J (2012) Variable expression and incomplete penetrance of developmental dysplasia of the hip: clinical challenge in a 71-member multigeneration family. J Arthroplasty 27: 527-532.

Filges I, Hall JG (2012) We are failing to identify disorders of fetal movement - why? Prenat Diagn 32: 919-920.

Filges I, Hall JG (2013) Failure to identify antenatal multiple congenital contractures and fetal akinesia proposal of guidelines to improve diagnosis. Prenat Diagn 33: 61-74.

Fisk NM, Tannirandorn Y, Nicolini U, Talbert DG, Rodeck CH (1990) Amniotic pressure in disorders of amniotic fluid volume. Obstet Gynecol 76: 210-214.

Fisk N, Ronderos-Dumit D, Tannirandorn Y, Nicolini U, Talbert D, Rodeck C (1992) Normal amniotic pressure throughout gestation. BJOG 99: 18-22.

Flynn AM, Kelly J, Mansfield H, Needham P, O'Conor M, Viegas O (1982) A randomized controlled trial of nonstress antepartum cardiotocography. BJOG 89: 427-433.

Fong BF, Buis AJ, Savelsbergh GJ, de Vries JI (2005a) Influence of breech presentation on the development of fetal arm posture. Early Hum Dev 81: 519-527.

Fong BF, Savelsbergh GJ, van Geijn HP, de Vries JI (2005b) Does intra-uterine environment influence fetal head-position preference?: A comparison between breech and cephalic presentation. Early Hum Dev 81: 507-517.

Fong B, Ledebt A, Zwart R, De Vries JI, Savelsbergh GJ (2008) Is there an effect of prenatal breech position on locomotion at 2.5 years? Early Hum Dev 84: 211-216.

Fong B, Savelsbergh GJP, Leijsen M, de Vries JIP (2009) The influence of prenatal breech presentation on neonatal leg posture. Early Hum Dev 85: 201-206.

Fries CL, Remedios AM (1995) The pathogenesis and diagnosis of canine hip dysplasia: a review. Can Vet J 36: 494-502.

Gadd RL (1966) The volume of the liquor amnii in normal and abnormal pregnancies. BJOG 73: 11-22.

Geerdink JJ, Hopkins B, Beek WJ, Heriza CB (1996) The organization of leg movements in preterm and fullterm infants after term age. Dev Psychobiol 29: 335-351.

Gillespie E (1950) Principles of uterine growth in pregnancy. Am J Obstet Gynecol 59: 949-959.

Giorgi M, Carriero A, Shefelbine SJ, Nowlan NC (2014) Mechanobiological simulations of prenatal joint morphogenesis. J Biomech 47: 989-995.

Goldberg JD, Chervenak FA, Lipman RA, Berkowitz RL (1986) Antenatal sonographic diagnosis of arthrogryposis multiplex congenita. Prenat Diagn 6: 45-49. 
Gonik B, Zhang N, Grimm MJ (2003a) Defining forces that are associated with shoulder dystocia: the use of a mathematic dynamic computer model. Am J Obstet Gynecol 188: 1068-1072.

Gonik B, Zhang N, Grimm MJ (2003b) Prediction of brachial plexus stretching during shoulder dystocia using a computer simulation model. Am J Obstet Gynecol 189: 1168-1172.

Guo W-Y, Ono S, Oi S, Shen S-H, Wong T-T, Chung H-W, Hung J-H (2006) Dynamic motion analysis of fetuses with central nervous system disorders by cine magnetic resonance imaging using fast imaging employing steadystate acquisition and parallel imaging: a preliminary result. J Neurosurg 105: 94-100.

Ha K, Buchan JG, Alvarado DM, Mccall K, Vydyanath A, Luther PK, Goldsmith MI, Dobbs MB, Gurnett CA (2013) MYBPC1 mutations impair skeletal muscle function in zebrafish models of arthrogryposis. Hum Mol Genet 22: 4967-4977.

Hadlock FP, Harrist RB, Sharman RS, Deter RL, Park SK (1985) Estimation of fetal weight with the use of head, body, and femur measurements--a prospective study. Am J Obstet Gynecol 151: 333-337.

Hall JG (2009) Pena-Shokeir phenotype (Fetal akinesia deformation sequence) revisited. Birth Defects Res A Clin Mol Teratol 85: 677-694.

Hall BK, Herring S (1990) Paralysis and growth of the musculoskeletal system in the embryonic chick. J Morphol 206: 45-56.

Hall J, Reed S, Driscoll E, Opitz JM (1983) Part I. Amyoplasia: a common, sporadic condition with congenital contractures. Am J Med Genet 15: 571-590.

Hall JG, Aldinger KA, Tanaka KI (2014) Amyoplasia revisited. Am J Med Genet A 164A: 700-730.

Hao Z, Dai J, Shi D, Xu Z, Chen D, Zhao B, Teng H, Jiang Q (2014) Association of a single nucleotide polymorphism in HOXB9 with developmental dysplasia of the hip: A case-control study. J Orthop Res 32: 179-182.

Hayat TTA, Nihat A, Martinez-Biarge M, McGuinness A, Allsop JM, Hajnal JV, Rutherford MA (2011) Optimization and Initial experience of a multisection balanced steady-state free precession cine sequence for the assessment of fetal behavior in utero. AJNR Am J Neuroradiol 32: 331-338.

Heegaard J, Beaupre G, Carter D (1999) Mechanically modulated cartilage growth may regulate joint surface morphogenesis. J Orthop Res 17: 509-517.

Heriza CB (1988) Comparison of leg movements in preterm infants at term with healthy full-term infants. Phys Ther 68: 1687-1693.

Hertogs K, Roberts AB, Cooper D, Griffin DR, Campbell S (1979) Maternal perception of fetal motor activity. Br Med J 2: 1183-1185.

Hijazi ZR, East CE (2009) Factors affecting maternal perception of fetal movement. Obstet Gynecol Surv 64: 489-497.

Hinderaker T, Daltveit AK, Irgens LM, Udén A, Reikeräs O (1994) The impact of intra-uterine factors on neonatal hip instability: An analysis of 1,059,479 children in Norway. Acta Orthop 65: 239-242.
Hogervorst T, Eilander W, Fikkers J, Meulenbelt I (2012) Hip ontogenesis: how evolution, genes, and load history shape hip morphotype and cartilotype. Clin Orthop Relat Res 470: 3284-3296.

Holen K, Tegnander A, Terjesen T, Johansen O, Eik-Nes S (1996) Ultrasonographic evaluation of breech presentation as a risk factor for hip dysplasia. Acta Paediatr 85: 225-229.

Hosseini A, Hogg D (1991) The effects of paralysis on skeletal development in the chick embryo. I. General effects. J Anat 177: 159-168.

Hu J, Klinich KD, Miller CS, Nazmi G, Pearlman MD, Schneider LW, Rupp JD (2009) Quantifying dynamic mechanical properties of human placenta tissue using optimization techniques with specimen-specific finiteelement models. J Biomech 42: 2528-2534.

Iwahara T, Ikeda A (1962) On the ipsilateral involvement of congenital muscular torticollis and congenital dislocation of the hip. J Jpn Orthop Assn 35: 1221-1226.

Jacobson L, Polizzi A, Vincent A (1998) An animal model of maternal antibodymediated arthrogryposis multiplex congenita (AMC). Ann NY Acad Sci 841: 565567.

Jago R (1970) Arthrogryposis following treatment of maternal tetanus with muscle relaxants. Arch Dis Child 45: 277-279.

Jansson LM, DiPietro J, Elko A (2005) Fetal response to maternal methadone administration. Am J Obstet Gynecol 193: 611-617.

Kahn J, Shwartz Y, Blitz E, Krief S, Sharir A, Breitel DA, Rattenbach R, Relaix F, Maire P, Rountree RB, Kingsley DM, Zelzer E (2009) Muscle contraction is necessary to maintain joint progenitor cell fate. Dev Cell 16: $734-743$.

Kirkinen P, Hervat R, Leisti J (1987) Early prenatal diagnosis of a lethal syndrome of multiple congenital contractures. Prenat Diagn 7: 189-196.

Langenskiöld A, Sarpio O, Michelsson J-E (1962) Experimental dislocation of the hip in the rabbit. J Bone Joint Surg Br 44: 209-215.

Lapeer R, Prager R (2001) Fetal head moulding: finite element analysis of a fetal skull subjected to uterine pressures during the first stage of labour. J Biomech 34: $1125-1133$.

Leck I (2000) Congenital dislocation of the hip. In: Wald N, Leck I (eds) Antenatal and Neonatal Screening, Oxford University Press, Oxford, pp 398-424.

Lewis P, Trudinger B, Mangez J (1978) Effect of maternal glucose ingestion on fetal breathing and body movements in late pregnancy. BJOG 85: 86-89.

Litmanovitz I, Dolfin T, Friedland O, Arnon S, Regev R, Shainkin-Kestenbaum R, Lis M, Eliakim A (2003) Early physical activity intervention prevents decrease of bone strength in very low birth weight infants. Pediatrics 112: 15-19.

Lowry CA, Donoghue VB, Murphy JF (2005) Auditing hip ultrasound screening of infants at increased risk of developmental dysplasia of the hip. Arch Dis Child 90: 579-581.

Lowry RB, Sibbald B, Bedard T, Hall JG (2010) Prevalence of multiple congenital contractures including 
arthrogryposis multiplex congenita in Alberta, Canada, and a strategy for classification and coding. Birth Defects Res A Clin Mol Teratol 88: 1057-1061.

Luterkort M, Persson PH, Polberger S, Bjerre I (1986) Hip joint instability in breech pregnancy. Acta Pædiatr Scand 75: 860-863.

Maclennan AH, Maclennan SC (1997) Symptomgiving pelvic girdle relaxation of pregnancy, postnatal pelvic joint syndrome and developmental dysplasia of the hip. Acta Obstet Gynecol Scand 76: 760-764.

Mahmoodian R, Leasure J, Gadikota H, Capaldi F, Siegler S (2009) Mechanical properties of human fetal talus. Clin Orthop Relat Res 467: 1186-1194.

Mahmoodian R, Leasure J, Philip P, Pleshko N, Capaldi F, Siegler S (2011) Changes in mechanics and composition of human talar cartilage anlagen during fetal development. Osteoarthritis Cartilage 19: 1199-1209.

Makepeace A, Fremont-Smith F, Dailey M, Carroll M (1931) The nature of the amniotic fluid. Surg Gynecol Obstet 53: 635-672.

Mangesi L, Hofmeyr G (2007) Fetal movement counting for assessment of fetal wellbeing. Cochrane Database Syst Rev 1: CD004909.

Manning F, Pugh EW, Boddy K (1975) Effect of cigarette smoking on fetal breathing movements in normal pregnancies. Br Med J 1: 552-553.

Manoogian SJ, Bisplinghoff JA, McNally C, Kemper AR, Santago AC, Duma SM (2008) Dynamic tensile properties of human placenta. J Biomech 41: 3436-3440.

Martins J, Pato M, Pires E, Jorge RN, Parente M, Mascarenhas T (2007) Finite element studies of the deformation of the pelvic floor. Ann NY Acad Sci 1101: 316-334.

McGowan J, Devoe LD, Searle N, Altman R (1987) The effects of long-and short-term maternal caffeine ingestion on human fetal breathing and body movements in term gestations. Am J Obstet Gynecol 157: 726-729.

McLeod W, Brien J, Loomis C, Carmichael L, Probert C, Patrick J (1983) Effect of maternal ethanol ingestion on fetal breathing movements, gross body movements, and heart rate at 37 to 40 weeks' gestational age. Am J Obstet Gynecol 145: 251-257.

McPherson GK, Kriewall TJ (1980a) Fetal head molding: an investigation utilizing a finite element model of the fetal parietal bone. J Biomech 13: 17-26.

McPherson GK, Kriewall TJ (1980b) The elastic modulus of fetal cranial bone: a first step towards an understanding of the biomechanics of fetal head molding. J Biomech 13: 9-16.

Michelsson J, Langenskiöld A (1972) Dislocation or subluxation of the hip. Regular sequels of immobilization of the knee in extension of young rabbits. J Bone Joint Surg Am 54: 1177-1186

Minors DS, Waterhouse JM (1979) The effect of maternal posture, meals and time of day on fetal movements. BJOG 86: 717-723.

Miyamoto Y, Mabuchi A, Shi D, Kubo T, Takatori Y, Saito S, Fujioka M, Sudo A, Uchida A, Yamamoto S (2007) A functional polymorphism in the $5^{\prime}$ UTR of GDF5 is associated with susceptibility to osteoarthritis. Nat Genet 39: $529-533$.
Moessinger AC (1983) Fetal akinesia deformation sequence: an animal model. Pediatrics 72: 857-863.

Moh W, Graham JM, Wadhawan I, Sanchez-Lara PA (2012) Extrinsic factors influencing fetal deformations and intrauterine growth restriction. J Pregnancy 2012: 750485.

Moyer-Mileur L, Luetkemeier M, Boomer L, Chan GM (1995) Effect of physical activity on bone mineralization in premature infants. J Pediatr 127: 620-625.

Moyer-Mileur L, Brunstetter V, McNaught T, Gill G, Chan G (2000) Daily physical activity program increases bone mineralization and growth in preterm very low birth weight infants. Pediatrics 106: 1088-1092.

Moyer Mileur LJ, Ball SD, Brunstetter VL, Chan GM (2008) Maternal-administered physical activity enhances bone mineral acquisition in premature very low birth weight infants. J Perinatol 28: 432-437.

Mulder EJ, Morssink LP, Van Der Schee T, Visser GH (1998) Acute maternal alcohol consumption disrupts behavioral state organization in the near-term fetus. Pediatr Res 44: 774-779.

Mulder E, Nikkels P, Visser G (2001) Fetal akinesia deformation sequence: behavioral development in a case of congenital myopathy. Ultrasound Obstet Gynecol 18: 253-257.

Muller G, Seddon H (1953) Late results of treatment of congenital dislocation of the hip. J Bone Joint Surg Br 35: 342-362.

Murray P, Drachman D (1969) The role of movement in the development of joints and related structures: the head and neck in the chick embryo. J Embryol Exp Morphol 22: 349-371.

Natale R, Nasello-Paterson C, Turliuk R (1985) Longitudinal measurements of fetal breathing, body movements, heart rate, and heart rate accelerations and decelerations at 24 to 32 weeks of gestation. Am J Obstet Gynecol 151: 256-263.

Nemec SF, Höftberger R, Nemec U, Bettelheim D, Brugger PC, Kasprian G, Amann G, Rotmensch S, Graham Jr JM, Rimoin DL (2011) Fetal akinesia and associated abnormalities on prenatal MRI. Prenat Diagn 31: 484-490.

Nishihara K, Horiuchi S, Eto H, Honda M (2008) A long-term monitoring of fetal movement at home using a newly developed sensor: an introduction of maternal micro-arousals evoked by fetal movement during maternal sleep. Early Hum Dev 84: 595-603.

Nowlan NC, Murphy P, Prendergast PJ (2007) Mechanobiology of embryonic limb development. Ann NY Acad Sci 1101: 389-411.

Nowlan NC, Murphy P, Prendergast PJ (2008a) A dynamic pattern of mechanical stimulation promotes ossification in avian embryonic long bones. J Biomech 41: 249-258.

Nowlan NC, Prendergast PJ, Murphy P (2008b) Identification of mechanosensitive genes during embryonic bone formation. PLoS Comput Biol 4: e1000250.

Nowlan NC, Bourdon C, Dumas G, Tajbakhsh S, Prendergast PJ, Murphy P (2010a) Developing bones are differentially affected by compromised skeletal muscle formation. Bone 46: 1275-1285.

Nowlan NC, Sharpe J, Roddy KA, Prendergast PJ, Murphy P (2010b) Mechanobiology of embryonic skeletal 
development: Insights from animal models. Birth Defects Res C Embryo Today 90: 203-213.

Nowlan NC, Dumas G, Tajbakhsh S, Prendergast PJ, Murphy P (2012) Biophysical stimuli induced by passive movements compensate for lack of skeletal muscle during embryonic skeletogenesis. Biomech Model Mechanobiol 11: 207-219.

Nowlan NC, Chandaria V, Sharpe J (2014) Immobilized chicks as a model system for early-onset developmental dysplasia of the hip. J Orthop Res 32: 777-785.

O'Rahilly R, Gardner E (1975) The timing and sequence of events in the development of the limbs in the human embryo. Anat Embryol 148: 1-23.

O’Sullivan O, Stephen G, Martindale E, Heazell AEP (2009) Predicting poor perinatal outcome in women who present with decreased fetal movements. J Obstet Gynaecol 29: 705-710.

Olesen AG, Svare JA (2004) Decreased fetal movements: background, assessment, and clinical management. Acta Obstet Gynecol Scand 83: 818-826.

Ortolani M (1937) Un segno poco noto e sua importanza per la diagnosi precoce di prelussazione congenita dell'anca. [A poorly noticed sign and it importance for the diagnosis of congenital predislocation of the hip.] Pediatria 45: 129-136.

Oyen M, Cook R, Calvin S (2004) Mechanical failure of human fetal membrane tissues. J Mater Sci Mater Med 15: 651-658.

Oyen ML, Cook RF, Stylianopoulos T, Barocas VH, Calvin SE, Landers DV (2005) Uniaxial and biaxial mechanical behavior of human amnion. J Mater Res 20: 2902-2909.

Oyen ML, Calvin SE, Landers DV (2006) Premature rupture of the fetal membranes: is the amnion the major determinant? Am J Obstet Gynecol 195: 510-515.

Pai A (1965) Developmental genetics of a lethal mutation, muscular dysgenesis (mdg), in the mouse. I. Genetic analysis and gross morphology. Dev Biol 11: 8292.

Palacios J, Rodriguez JI (1990) Extrinsic fetal akinesia and skeletal development: a study in oligohydramnios sequence. Teratology 42: 1-5.

Paladini D, Tartaglione A, Agangi A, Foglia S, Martinelli P, Nappi C (2001) Pena-Shokeir phenotype with variable onset in three consecutive pregnancies. Ultrasound Obstet Gynecol 17: 163-165.

Papini M, Zdero R, Schemitsch EH, Zalzal P (2007) The biomechanics of human femurs in axial and torsional loading: comparison of finite element analysis, human cadaveric femurs, and synthetic femurs. J Biomech Eng 129: 12-19.

Parente M, Jorge RN, Mascarenhas T, Fernandes A, Martins J (2008) Deformation of the pelvic floor muscles during a vaginal delivery. Int Urogynecol J 19: 65-71.

Patrick J, Campbell K, Carmichael L, Natale R, Richardson B (1982) Patterns of gross fetal body movements over 24-hour observation intervals during the last 10 weeks of pregnancy. Am J Obstet Gynecol 142: 363-371.

Pavlik A (1992) The functional method of treatment using a harness with stirrups as the primary method of conservative therapy for infants with congenital dislocation of the hip. Clin Orthop Relat Res 281: 4-10.

American Academy of Pediatrics, Committee on Quality Improvement, Subcommittee on Developmental Dysplasia of the Hip (2000) Clinical practice guideline: early detection of developmental dysplasia of the hip. Pediatrics 105: 896-905.

Pei X, Mo Y, Ning B, Yuan Z, Peng L, Ma R (2014) The role of TGF $\beta 1$ stimulating ROCK I signal pathway to reorganize actin in a rat experimental model of developmental dysplasia of the hip. Mol Cell Biochem 391: 1-9.

Piyamongkol W, Trungtawatchai S, Chanprapaph P, Tongsong T (2006) Comparison of the manual stimulation test and the nonstress test: a randomized controlled trial. Chot Mai Het Thang Phaet 89: 1999-2002.

Ráliš Z, McKibbin B (1973) Changes in shape of the human hip joint during its development and their relation to its stability. J Bone Joint Surg Br 55: 780-785.

Ravenscroft G, Sollis E, Charles AK, North KN, Baynam G, Laing NG (2011) Fetal akinesia: review of the genetics of the neuromuscular causes. J Med Genetics 48: 793-801.

Rayburn WF, McKean HE (1980) Maternal perception of fetal movement and perinatal outcome. Obstet Gynecol 56: 161-164.

Reijman M, Hazes J, Pols H, Koes B, Bierma-Zeinstra S (2005) Acetabular dysplasia predicts incident osteoarthritis of the hip: the Rotterdam study. Arthritis Rheum 52: 787793.

Riboni G, Bellini A, Serantoni S, Rognoni E, Bisanti L (2003) Ultrasound screening for developmental dysplasia of the hip. Pediatr Radiol 33: 475-481.

Riser WH, Rhodes WH, Newton CD (1985) Hip dysplasia. In: Newton CD, Nunamaker DM (eds) Textbook of Small Animal Orthopaedics, JB Lippincott, Philadelphia, Chapter 83.

Ritchie K (1980) The fetal response to changes in the composition of maternal inspired air in human pregnancy. Semin Perinatol, 4: 295-299.

Roddy KA, Kelly GM, van Es MH, Murphy P, Prendergast PJ (2011a) Dynamic patterns of mechanical stimulation co-localise with growth and cell proliferation during morphogenesis in the avian embryonic knee joint. J Biomech 44: 143-149.

Roddy KA, Prendergast PJ, Murphy P (2011b) Mechanical influences on morphogenesis of the knee joint revealed through morphological, molecular and computational analysis of immobilised embryos. PLoS One 6: e17526.

Rodríguez J, Garcia-Alix A, Palacios J, Paniagua R (1988a) Changes in the long bones due to fetal immobility caused by neuromuscular disease. A radiographic and histological study. J Bone Joint Surg Am 70: 1052-1060.

Rodríguez JI, Palacios J, García-Alix A, Pastor I, Paniagua R (1988b) Effects of immobilization on fetal bone development. A morphometric study in newborns with congenital neuromuscular diseases with intrauterine onset. Calcif Tissue Int 43: 335-339.

Roposch A, Stöhr KK, Dobson M (2009) The effect of the femoral head ossific nucleus in the treatment of 
developmental dysplasia of the hipa meta-analysis. J Bone Joint Surg Am 91: 911-918.

Rot-Nikcevic I, Reddy T, Downing KJ, Belliveau AC, Hallgrimsson B, Hall BK, Kablar B (2006) Myf5-/:Myod-/- amyogenic fetuses reveal the importance of early contraction and static loading by striated muscle in mouse skeletogenesis. Dev Genes Evol 216: 1-9.

Rouault K, Scotet V, Autret S, Gaucher F, Dubrana F, Tanguy D, Yaacoub El Rassi C, Fenoll B, Férec C (2010) Evidence of association between GDF5 polymorphisms and congenital dislocation of the hip in a Caucasian population. Osteoarthritis Cartilage 18: 1144-1149.

Ruano R, Dumez Y, Dommergues M (2003) Threedimensional ultrasonographic appearance of the fetal akinesia deformation sequence. J Ultrasound Med 22: 593-599.

Ryo E, Nishihara K, Matsumoto S, Kamata H (2012) A new method for long-term home monitoring of fetal movement by pregnant women themselves. Med Eng Phys 34: $566-572$.

Salisbury AL, Ponder KL, Padbury JF, Lester BM (2009) Fetal effects of psychoactive drugs. Clin Perinatol 36: 595-619.

Salter R (1968) Etiology, pathogenesis and possible prevention of congenital dislocation of the hip. Can Med Assoc J 98: 933-945.

Sandell LJ (2012) Etiology of osteoarthritis: genetics and synovial joint development. Nat Rev Rheumatol 8 : 77-89.

Segal LS, Boal DK, Borthwick L, Clark MW, Localio AR, Schwentker EP (1999a) Avascular necrosis after treatment of DDH: the protective influence of the ossific nucleus. J Pediatr Orthop 19: 177-184.

Segal LS, Schneider DJ, Berlin JM, Bruno A, Davis BR, Jacobs CR (1999b) The contribution of the ossific nucleus to the structural stiffness of the capital femoral epiphysis: a porcine model for DDH. J Pediatr Orthop 19: 433-437.

Sekulić S, Zarkov M, Slankamenac P, Bozić K, Vejnović T, Novakov-Mikić A (2009) Decreased expression of the righting reflex and locomotor movements in breechpresenting newborns in the first days of life. Early Hum Dev 85: 263-266.

Sepulveda W, Stagiannis KD, Cox PM, Wigglesworth JS, Fisk NM (1995) Prenatal findings in generalized amyoplasia. Prenat Diagn 15: 660-664.

Sharp M (2007) Bone disease of prematurity. Early Hum Dev 83: 653-658.

Sharpe J, Ahlgren U, Perry P, Hill B, Ross A, HecksherSorensen J, Baldock R, Davidson D (2002) Optical projection tomography as a tool for 3D microscopy and gene expression studies. Science 296: 541-545.

Shefelbine SJ, Carter DR (2004) Mechanobiological predictions of growth front morphology in developmental hip dysplasia. J Orthop Res 22: 346-352.

Sherer DM, Sanko SR, Metlay LA, Woods JR (1992) Absent fetal movement response with a blunted cardioacceleratory fetal response to external vibratory acoustic stimulation in a fetus with the Pena-Shokeir syndrome (fetal akinesia and hypokinesia sequence). Am J Perinatol 9: 1-4.
Sival DA, Visser GH, Prechtl HF (1990) Does reduction of amniotic fluid affect fetal movements? Early Hum Dev 23: 233-246.

Sival DA, Prechtl HF, Sonder GH, Touwen BC (1993) The effect of intra-uterine breech position on postnatal motor functions of the lower limbs. Early Hum Dev 32: 161-176.

Southam L, Rodriguez-Lopez J, Wilkins JM, PomboSuarez M, Snelling S, Gomez-Reino JJ, Chapman K, Gonzalez A, Loughlin J (2007) An SNP in the 5'-UTR of GDF5 is associated with osteoarthritis susceptibility in Europeans and with in vivo differences in allelic expression in articular cartilage. Hum Mol Genet 16: 2226-2232.

Stevenson DA, Mineau G, Kerber RA, Viskochil DH, Schaefer C, Roach JW (2009) Familial predisposition to developmental dysplasia of the hip. J Pediatr Orthop 29: 463-466.

Swinyard CA, Bleck EE (1985) The etiology of arthrogryposis (multiple congenital contracture). Clin Orthop Relat Res 194: 15-29.

Tan KH, Sabapathy A (2001) Fetal manipulation for facilitating tests of fetal wellbeing. Cochrane Database Syst Rev 4: CD003396.

Tan K, Smyth R (2001) Fetal vibroacoustic stimulation for facilitation of tests of fetal wellbeing. Cochrane Database Syst Rev 1: CD002963.

Ten Hof J, Nijhuis I, Nijhuis J, Narayan H, Taylor D, Visser G, Mulder E (1999) Quantitative analysis of fetal general movements: methodological considerations. Early Hum Dev 56: 57-73.

Ten Hof J, Nijhuis IJ, Mulder EJ, Nijhuis JG, Narayan H, Taylor DJ, Westers P, Visser GH (2002) Longitudinal study of fetal body movements: nomograms, intrafetal consistency, and relationship with episodes of heart rate patterns a and B. Pediatr Res 52: 568-575.

Tian W, Zhao L, Suo P, Wang J, Cheng L, Cheng Z, Jia J, Kan S, Wang B, Ma X (2012) Association analysis between HOXD9 genes and the development of developmental dysplasia of the hip in Chinese female Han population. BMC Musculoskelet Disord 13: 59-59.

Tongsong T, Chanprapaph P, Khunamornpong S (2000) Prenatal ultrasound of regional akinesia with Pena-Shokier phenotype. Prenat Diagn 20: 422-425.

Vaes R, Rivadeneira F, Kerkhof J, Hofman A, Pols H, Uitterlinden A, van Meurs J (2009) Genetic variation in the GDF5 region is associated with osteoarthritis, height, hip axis length and fracture risk: the Rotterdam study. Ann Rheum Dis 68: 1754-1760.

Wang E, Liu T, Li J, Edmonds E, Zhao Q, Zhang L, Zhao X, Wang K (2012) Does swaddling influence developmental dysplasia of the hip?: An experimental study of the traditional straight-leg swaddling model in neonatal rats. J Bone Joint Surg Am 94: 1071-1077.

Wedge J, Wasylenko M (1979) The natural history of congenital disease of the hip. J Bone Joint Surg Br 61: 334-338.

Weinstein S (1987) Natural history of congenital hip dislocation $(\mathrm{CDH})$ and hip dysplasia. Clin Orthop Relat Res 225: 62-76. 
Whitworth M, Fisher M, Heazell A (2011) Reduced fetal movements. Royal College of Obstetricians and Gynaecologists, London, Guideline 57.

Wilkinson JA (1963) Prime factors in the etiology of congenital dislocation of the hip. J Bone Joint Surg Br 45: 268-283.

Witters I, Moerman P, Fryns JP (2002) Fetal akinesia deformation sequence: a study of 30 consecutive in utero diagnoses. Am J Med Genet 113: 23-28.

Wood C (1964) Physiology of uterine contractions. BJOG 71: 360-373.

Wood C (1970) Weightlessness: its implications for the human fetus. BJOG 77: 333-336.

Wynne-Davies R (1970) Acetabular dysplasia and familial joint laxity: two etiological factors in congenital dislocation of the hip: a review of 589 patients and their families. J Bone Joint Surg-Br 52: 704-716.

Wynne-Davies R, Lloyd-Roberts G (1976) Arthrogryposis multiplex congenita. Search for prenatal factors in 66 sporadic cases. Arch Dis Child 51: 618-623.

Yamamuro T, Ishida K (1984) Recent advances in the prevention, early diagnosis, and treatment of congenital dislocation of the hip in Japan. Clin Orthop Relat Res 184: 34-40.

Yfantis H, Nonaka D, Castellani R, Harman C, Sun CC (2002) Heterogeneity in fetal akinesia deformation sequence (FADS): autopsy confirmation in three 20-21week fetuses. Prenat Diagn 22: 42-47.

Zoia S, Blason L, D'Ottavio G, Bulgheroni M, Pezzetta E, Scabar A, Castiello U (2007) Evidence of early development of action planning in the human fetus: a kinematic study. Exp Brain Res 176: 217-226.

\section{Discussion with Reviewers}

Reviewer I: How do these findings impact on how we respond to mothers' reports of reduced foetal movement? Author: When a mother reports reduced foetal movements, it is usually because she has noticed a change from the normal baseline pattern of movements, where that baseline is normal for the current pregnancy. Therefore, in cases of FADS or arthrogryposis, the mother may not self-refer for reduced movements due to the fact that the level of movement might have been reduced for an extended period of time. An enhanced emphasis on assessing foetal movements, whether with ultrasound, MRI or emerging wearable sensor technologies, would facilitate better prenatal diagnosis of musculoskeletal conditions related to prenatal movements, such as arthrogryposis, and has the potential (in the long term) to determine a threshold for a healthy amount or pattern of foetal movements which would assist with management of mothers reporting reduced foetal movement.

Reviewer I: How should we counsel women who have known foetal abnormalities about the effects of foetal movement?

Author: For parents of children with abnormalities such as arthrogryposis or DDH, it might be helpful to understand why one or more joints have an abnormal shape or position, particularly where no genetic abnormalities are diagnosed. Perhaps this review, which is focussed on the effects of abnormal movements on the musculoskeletal system, will be a useful resource for clinicians when counselling parents of children affected by such conditions.

Reviewer II: In which species do the authors consider to perform the future investigation on biomechanical effects of uterine restraint over time?

Author: Separating the influences of intra-uterine space and amniotic fluid volume on foetal movement is highly challenging in animal model systems, as when a quantity of amniotic fluid is removed (as has been performed previously (Palacios et al., 1992)), the available space is also reduced. We believe that computational modelling, for example, using foetal cine-MRI, will be the best tool with which to quantify the degree of restraint or restriction of the foetus (e.g., different types of breech foetal positions) and the volume of fluid available, in order to investigate correlations between these parameters with the patterns and range of movements.

Reviewer II: Which species have sufficient amniotic fluid during pregnancy that reduction near term age occurs as in the human?

Author: Amniotic fluid volume changes during murine gestation exhibit similar trends as in human gestation, with an increase in fluid volume up until roughly three quarters through gestation, followed by a decrease up until birth (Beall et al., 2007a; Beall et al., 2007b), and it is likely that most mammalian species exhibit similar trends.

\section{Additional References}

Beall M, Wang S, Yang B, Chaudhri N, Amidi F, Ross M (2007b) Placental and membrane aquaporin water channels: correlation with amniotic fluid volume and composition. Placenta 28: 421-428.

Palacios J, Rodríguez JI, Ruiz A, Sanchez M, Alvarez I, Demiguel E (1992) Long bone development in extrinsic fetal akinesia: an experimental study in rat fetuses subjected to oligohydramnios. Teratology 46: 79-84. 